\title{
An experimental analysis of flow boiling and pressure drop in a brazed plate heat exchanger for organic Rankine cycle power systems
}

Desideri, Adriano; Zhang, Ji; Kærn, Martin Ryhl; Ommen, Torben Schmidt; Wronski, Jorrit; Lemort, Vincent; Haglind, Fredrik

Published in:

International Journal of Heat and Mass Transfer

Link to article, DOI:

10.1016/j.jheatmasstransfer.2017.05.063

Publication date:

2017

Document Version

Peer reviewed version

Link back to DTU Orbit

Citation (APA):

Desideri, A., Zhang, J., Kærn, M. R., Ommen, T. S., Wronski, J., Lemort, V., \& Haglind, F. (2017). An experimental analysis of flow boiling and pressure drop in a brazed plate heat exchanger for organic Rankine cycle power systems. International Journal of Heat and Mass Transfer, 113, 6-21.

https://doi.org/10.1016/j.ijheatmasstransfer.2017.05.063

\section{General rights}

Copyright and moral rights for the publications made accessible in the public portal are retained by the authors and/or other copyright owners and it is a condition of accessing publications that users recognise and abide by the legal requirements associated with these rights.

- Users may download and print one copy of any publication from the public portal for the purpose of private study or research.

- You may not further distribute the material or use it for any profit-making activity or commercial gain

- You may freely distribute the URL identifying the publication in the public portal 


\title{
An experimental analysis of flow boiling and pressure drop in a brazed plate heat exchanger for organic Rankine cycle power systems
}

\author{
Adriano Desideri ${ }^{\mathrm{a}, *}$, Ji Zhang ${ }^{\mathrm{b},}$, Martin Ryhl Kærn ${ }^{\mathrm{b}}$, Torben Schmidt Ommen ${ }^{\mathrm{b}}$, Jorrit Wronski ${ }^{\mathrm{c},}$, Vincent Lemort ${ }^{\mathrm{a},}$ \\ Fredrik Haglind ${ }^{\mathrm{b}}$, \\ ${ }^{a}$ Thermodynamics laboratory, University of Liège, Campus du Sart Tilman, B49, B-4000 Liège, Belgium \\ ${ }^{b}$ Department of Mechanical Engineering, Technical University of Denmark, Nils Koppels Allé, Building 403, 2800 Kongens Lyngby, Denmark \\ ${ }^{c} I P U$, Kongens Lyngby, Denmark
}

\begin{abstract}
Organic Rankine cycle power systems for low quality waste heat recovery applications can play a major role in achieving targets of increasing industrial processes efficiency and thus reducing the emissions of greenhouse gases. Low capacity organic Rankine cycle systems are equipped with brazed plate heat exchangers which allows for efficient heat transfer with a compact design. Accurate heat transfer correlations characterizing these devices are required from the design phase to the development of model-based control strategies. In this paper, the experimental heat transfer coefficient and pressure drop during vaporization at typical temperatures for low quality waste heat recovery organic Rankine cycle systems are presented for the working fluids HFC-245fa and HFO-1233zd. The experiments were carried out at saturation temperatures of $100^{\circ} \mathrm{C}, 115^{\circ} \mathrm{C}$ and $130^{\circ} \mathrm{C}$ and inlet and outlet qualities ranging between 0.1 0.4 and 0.5-1 respectively. The experimental heat transfer coefficients and frictional pressure drop were compared with well-known correlations and new ones are developed. The results indicated weak sensitivity of the heat transfer coefficients to the saturation temperature and were characterized by similar values for the two fluids. The frictional pressure drop showed a linear dependence with mean quality and increased as the saturation temperature decreased.
\end{abstract}

Keywords: two-phase heat transfer, boiling, pressure drop, organic Rankine cycle, experimental comparison

\section{Introduction}

In recent years, the consensus over anthropogenic climate change [1-3] as well as the rising prices for heat and electricity [4] are driving a global transition towards a green energy based economy. Furthermore, as a result of electricity sector liberalization polices, undertaken by several countries worldwide [5], distributed generation solutions are experiencing a significant growth [6]. In this context, many studies have underlined the potential of waste heat recovery from industrial processes in reducing both energy costs and associated emissions [7, 8]. In particular, it has been shown that a significant amount of the available industrial waste heat is at low temperature $\left(<200^{\circ} \mathrm{C}\right)$ which makes it difficult to harvest [9-11]. Among the available technologies for low quality waste heat recovery (WHR), organic Rankine cycle (ORC) power systems have been proven to be a viable solution in the large power capacity range, say from hundreds of $\mathrm{kW}$ to a few $\mathrm{MW}[12,13]$. In recent years, there has been an increasing interest for investigating the potential of small scale ORC units for low temperature WHR, say from few $\mathrm{kW}$ to tens of $\mathrm{kW}$ [1416]. Due to the non-constant nature of the wasted thermal energy available from industrial facilities, a specific control strategy ensuring safe and optimal operation of the ORC unit in any conditions are required. Before a control system can be designed the dynamic behaviour of the ORC unit needs to be well investigated [17][18]. As the thermal inertia of the heat exchangers determines the characteristic transients of the power unit [19], specific heat transfer coefficient correlations play a fundamental role in the model accuracy.

\footnotetext{
${ }^{*}$ Corresponding author

Email address: adesideri@ulg. ac . be (Adriano Desideri)
} 


\begin{tabular}{|c|c|c|c|}
\hline Nomenclature & & $\mathrm{ch}$ & channel \\
\hline Acronyms & & $\mathrm{v}$ & saturated vapour \\
\hline $\mathrm{HFC}$ & hydrofluorocarbon & 1 & saturated liquid \\
\hline $\mathrm{HFO}$ & hydrofluoroolefin & vap & vaporization \\
\hline WHR & waste heat recovery & Symbols & \\
\hline ORC & organic Rankine cycle & $p$ & pressure (bar) \\
\hline $\mathrm{HX}$ & heat exchanger & $T$ & temperature $\left({ }^{\circ} \mathrm{C}\right)$ \\
\hline BPHX & brazed plate heat exchanger & $\rho$ & density $\left(\mathrm{kg} \mathrm{m}^{-3}\right)$ \\
\hline $\mathrm{TC}$ & thermocouple & $\mu$ & viscosity (Pa s) \\
\hline PT & pressure transmitter & $k$ & thermal conductivity $\left(\mathrm{W} \mathrm{m} \mathrm{m}^{-1} \mathrm{k}^{-1}\right.$ ) \\
\hline DPS & differential pressure sensor & $h$ & specific enthalpy $\left(\mathrm{J} \mathrm{kg}^{-1}\right)$ \\
\hline CFM & Coriolis flow meter & $\alpha$ & fluid heat transfer coeff. $\left(\mathrm{W} \mathrm{m}^{-2} \mathrm{k}^{-1}\right.$ ) \\
\hline TFM & turbine flow meter & $U$ & overall heat transfer coeff. ( $\mathrm{W} \mathrm{m}^{-2} \mathrm{k}^{-1}$ ) \\
\hline MFM & magnetic flow meter & $\dot{Q}$ & thermal power $(\mathrm{W})$ \\
\hline AV & automatic valve & $\dot{q}$ & thermal flux $\left(\mathrm{W} \mathrm{m}^{-2}\right)$ \\
\hline MV & manual valve & $\dot{m}$ & mass flow rate $\left(\mathrm{kg} \mathrm{s}^{-1}\right)$ \\
\hline $\mathrm{R}$ & refrigerant & $G$ & $\operatorname{mass}$ flux $\left(\mathrm{kg} \mathrm{s}^{-1} \mathrm{~m}^{-2}\right)$ \\
\hline Subscripts & & $c_{\mathrm{p}}$ & specific heat capacity $\left(\mathrm{J} \mathrm{kg}^{-1} \mathrm{~K}^{-1}\right)$ \\
\hline su & supply & $X$ & vapour quality (-) \\
\hline ex & exit & $l_{\mathrm{p}}$ & wall thickness (m) \\
\hline wf & working fluid & $d_{\mathrm{h}}$ & hydraulic diameter (m) \\
\hline hf & hot fluid & $\operatorname{Re}$ & Reynolds number (-) \\
\hline wat & water & $\operatorname{Pr}$ & Prandtl number (-) \\
\hline eva & evaporator & We & Weber number (-) \\
\hline meas & measured & Bo & boiling number (-) \\
\hline $\mathrm{m}$ & mean & $\mathrm{Bd}$ & Bond number (-) \\
\hline $\mathrm{p}$ & plate & $\mathrm{Nu}$ & Nusselt number (-) \\
\hline
\end{tabular}

In an ORC power system, the evaporator design and heat transfer performance plays a major role for the overall system efficiency. An effective evaporating heat transfer leads to higher expander inlet temperature and thus better cycle efficiency. Validated evaporation heat transfer correlations for ORC systems are therefore necessary from the early design stage to the development and testing of efficient model-based control strategies. Despite the broad use of brazed plate heat exchangers (BPHX) for small ORC systems, the available literature covering the performance of these devices at the typical evaporation temperatures of ORC power units for low quality WHR is scarce [20] and no heat transfer correlations for high temperature evaporation exist [21]. Most of the literature reporting heat transfer characteristics for plate heat exchangers with non-conventional fluids are related to the refrigeration field where the vaporization conditions are far from the ones characterizing ORC power units.

It is generally accepted by the scientific community to consider the nucleate and convective heat transfer phenomena as the two main drivers in thermal energy transfer during evaporation [22]. Three main approaches taking into account the two boiling effects have been developed in the past, namely the superposition, the asymptotic and the enhancement model [23, 24]. Although these approaches have been originally developed for in-tube flow boiling, they are often used in plate heat exchangers experiments by adjusting the empirical coefficients to fit the experimental data [21]. Since their invention in the late 19th century, plate heat exchangers have been subject to scientific investigation. In 1981, Danilova et al. [25] presented one of the first flow boiling study on a plate heat exchanger with refrigerants HFC-12, HFC-22, HFC-113 and ammonia. A linear dependence between heat transfer coefficient and vapor quality and mass flux was shown. In 1995, Thonon et al. [26] proposed a method to identify the transition between the two boiling regimes and suggested that the nucleate phenomenon is expected to dominate over the evaporation heat transfer at high pressures.

In the last two decades, the innovative brazing manufacturing process allowed raising the efficiency and lowering the costs. The increasing interest of brazed plate heat exchangers led to significant experimental work to characterize their performances during flow boiling. Yan and Lin [27] and Hsieh and Lin [28] experimentally investigated the 
evaporation heat transfer and frictional pressure drop of HFC-134a during saturated flow boiling in a vertical plate heat exchanger. The effect of saturation temperature, heat flux, mass flux and vapour quality was analysed. Flow visualization through a transparent outlet plate showed that the flow remained turbulent also at very low Reynolds number. Empirical correlations for the heat transfer coefficient and the frictional pressure drop as a function of the Reynolds and the Boiling number were presented. A correlation based on the superposition method for predicting flow boiling data of HFC-410a was later presented by Hsieh and Lin [29]. Han et al. [30] performed an experimental investigation on HFC-410a and HFC-22 during flow boiling in brazed plate heat exchangers. The effect of different chevron angle was analysed at different mass fluxes, operating pressures, vapour qualities and the heat fluxes. Empirical correlations based on the ones developed by Hsieh and Lin [28] were derived by including a term accounting for the different geometries. Palm et al. [31] studied the experimental single and two-phase heat transfer coefficients in brazed plate heat exchangers for HFC-22 and HFC-134a. Their results support the Thonon assumptions, furthermore they found that the Cooper pool boiling correlation [32] well correlated the experimental data. Longo et al. [33] presented experimental data for HFC-134a, 410a and 236fa vaporization inside BPHX at typical evaporation temperature for traditional heat pump applications. The experimental heat transfer coefficients resulted well predicted by the Cooper [32] and Gorenflo [34] correlations for HFC-134a, 410a and slightly under-predicted for 236fa, indicating that the nucleate boiling phenomena controlled the vaporization of HFC-134a and 410a, while HFC-236fa was influenced by convective boiling. Linear dependency of the frictional pressure drop to the kinetic energy per unit of volume was found. In a later study, isobutane, propane and propylene vaprization inside brazed plate heat exchanger was investigated [35] for different heat fluxes, mass fluxes, operating pressures and vapour inlet and outlet conditions. Also in this case a linear dependence of the frictional pressure drop with the kinetic energy per unit of volume was demonstrated. Nucleate boiling was found to be the predominant effect during the experiments. This hypothesis was confirmed through comparison with the Thonon et al. [26] criterion. Khan et al. [36] investigated the evaporation heat transfer and pressure drop of Ammonia in a $30^{\circ}$ chevron plate heat exchanger. The effect of saturation temperature, heat flux and mass flux was analysed. Empirical correlations for the heat transfer coefficient and the frictional pressure drop were proposed based on equivalent Reynolds and Boiling numbers. Recently, Amalfi et al. [21] presented an in-depth overview of experimental data and prediction methods for evaporation heat transfer in plate heat exchangers. Based on the collected experimental database heat transfer and pressure drop correlations were derived through an adimensional prediction method. The interested reader is referred to [21] for an in depth literature review of available experimental work on evaporation in brazed plate heat exchangers.

In the present paper, the authors investigated the heat transfer and pressure drop performance during evaporation in a small brazed plate heat exchanger of two low critical temperature organic fluids HFC-245fa and HFO-1233zd. The former is a well-known hydrofluorocarbon used in the majority of the recently introduced small capacity low temperature ORC systems [37], the latter is a hydrofluroolefine which has been lately brought to the market as a low global warming potential (GWP) alternative to HFC-245fa [38]. The experimental data were collected on a test-rig equipped with seven BPHXs that has been recently built at the Department of Mechanical Engineering Technical University of Denmark (DTU). The facility allows running experimental tests to characterize the thermal phenomena driving the evaporation and condensation of non-conventional low critical temperature fluids in the working conditions of high temperature heat pumps and low temperature ORC systems. Preliminary experimental results with HFC-134a as working fluids were presented in Desideri et al. [39]. More detailed experimental data covering the vaporizaiton of HFC-134a, HFO-1234yf and HFO-1234ze at $60-80^{\circ} \mathrm{C}$ are presented in Zhang et al. [40]. In the present work the effects of mass flux, saturation pressure and evaporator outlet conditions on the two low critical temperature fluids, HFC-245fa and HFO-1233zd, were investigated. Several heat transfer and frictional pressure drop available from the literature were compared against the experimental data and new correlations following the method presented in [41] were derived. The article is organized as follows: section 2 describes the experimental facility available at DTU, while in section 3 the methodology to analyse the data is presented. The results are presented and analysed in section 4 and the main conclusions are outlined in section 5.

\section{Experimental facility}

The process flow diagram and the front view of the heat exchanger (HX) test-rig are shown in figures 1 and 2 respectively. The experimental rig comprises three loops: the working fluid in black, the cooling fluid in blue and the heating fluid in red. Six brazed plate heat exchangers connected in series are installed in the working fluid loop. A 


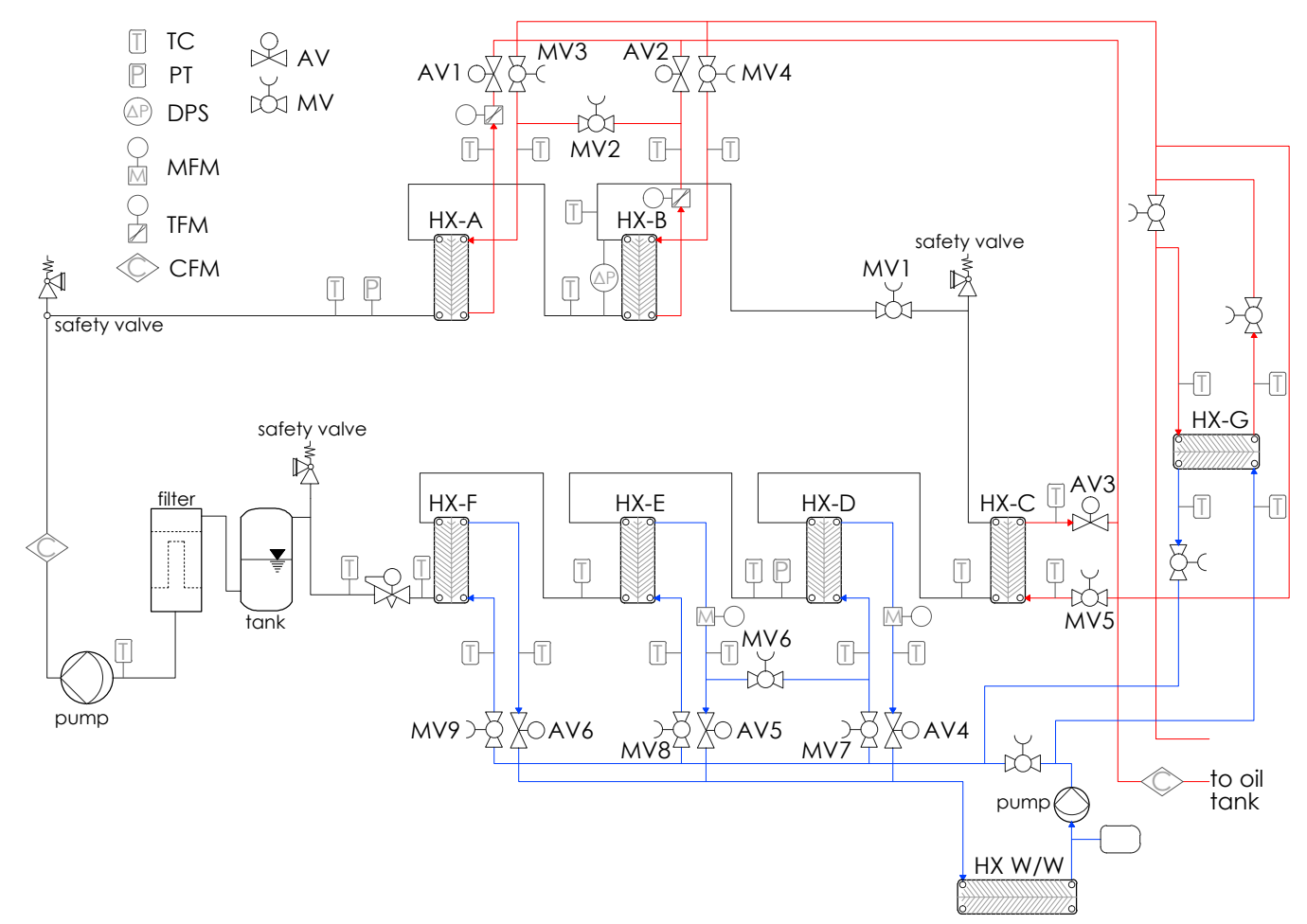

Figure 1: Process flow diagram and sensor position of the HX test rig. CFM: Coriolis flow meter. TFM: turbine flow meter. MFM: magnetic flow meter. TC: thermocouple. PT: pressure transmitter. DPS: differential pressure sensor. AV: automatic valve. MV: manual valve

seventh BPHX, HX-G, is installed in the set up between the heating and the cooling loops. This heat exchanger was used to derive the heat transfer correlation of the Wilson-plot [42] based experiments as explained in section 3 .

The cooling and heating circuits are closed loops using water and thermal oil Texatherm 22 (TX22) [43] as heat transfer fluids respectively. In the cooling loop, a volumetric pump ensures a stable water flow rate which rejects the thermal energy absorbed in HX-G,-D,-E,-F to the cooling network system via the BPHE HX W/W. Three automatic valves (AV4-AV5-AV6) installed at the outlet of HX-D,-E and-F allow controlling the mass flow rate, while five manually controlled valves allow for series or parallel loop configurations. The heating loop comprises a tank with six electrical heaters. A variable speed centrifugal pump circulates the oil through HX-A,-B,-C and -G. Three automatic valves (AV1-AV2-AV3) installed at the outlet of HX-A,-B and-C allow controlling the oil mass flow rate, while six manual valves allow for series and parallel loop configurations. As an example, the oil side of HX-A and HX-B can be arranged in a series configuration by opening MV2, MV4 and by closing MV3, while a parallel configuration is achieved by opening MV3 MV4, and by closing MV2. Referring to the bottom left side of figure 1, during the experimental campaign the working fluid was pumped from the receiver tank through the preheater HX-A and the evaporator HX-B, where it was partially evaporated to get a defined value of vapour quality. The fluid was then flashed by the expansion valve MV1 and entered the low pressure evaporator HX-C, the de-superheater HX-D, the condenser HX-E and the sub-cooler HX-F. The fluid in liquid phase was stored in the receiver tank at the outlet of HX-F. A filter placed at the pump inlet protects the machine from any solid residues present in the fluid. The variable speed volumetric pump allowed controlling the working fluid flow rate. The evaporating pressure was regulated by the expansion valve, MV1. In the cooling circuit, the volumetric pump was run at full speed and the mass flow rate was regulated adjusting the automatic valves AV4-AV5-AV6. The oil mass flow rate was regulated varying the speed of the centrifugal pump and the automatic valves AV1-AV2-AV3. Calibrated T-type thermocouples were used to measure the temperature of the working fluid, the cooling water and the thermal oil at the inlet and the outlet of each component. The thermocouples were calibrated by the authors based on the international scale of 1990 (ITS-90) [44] and using as a reference a platinum resistance thermometer. The working fluid pressure at the inlet of the preheater 


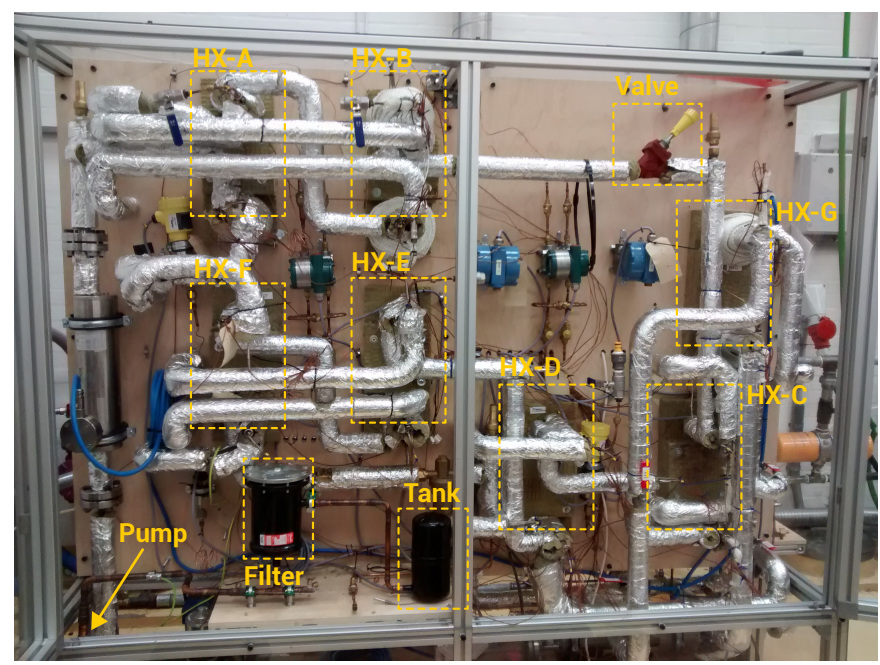

Figure 2: Front view of the HX test rig.

HX-A was measured by a pressure transmitter, whereas the refrigerant pressure drop through the evaporator HX-B was measured with a differential pressure sensor. The working fluid mass flow rate and density were measured at the pump outlet with a Coriolis flow meter. Two turbine volume flow meters were used to measure the oil volume flow rate at the outlet of HX-A and -B. A Coriolis flow meter installed on the return pipe from the test-rig to the oil tank measured the oil mass flow rate and density. The water volume flow rate was measured at HX-D and HX-E outlets by two magnetic volume flow meters. The uncertainty of the sensors are reported in Table 1. A PLC was used for basic

Table 1: Range and precision of the measurement devices. $k$ : coverage factor. CFM: Coriolis flow meter. TFM: turbine flow meter. MFM: magnetic flow meter. TC: thermocouple. PT: pressure transmitter. DPS: differential pressure sensor.

\begin{tabular}{llccc}
\hline Variable & Device type & Model & Range & Uncertainty $(k=2)$ \\
\hline$\dot{m}_{\mathrm{wf}}$ & CFM & Siemens 2100 DI6 & $0-0.15 \mathrm{~kg} \mathrm{~s}^{-1}$ & $\pm 0.06 \%$ \\
$\dot{m}_{\mathrm{hf}}$ & CFM & Siemens 2100 DI15 & $0-0.8 \mathrm{~kg} \mathrm{~s}^{-1}$ & $\pm 0.02 \%$ \\
$\dot{V}_{\text {oil }}$ & TFM & GL flow - LX13 & $2-201 \mathrm{~min}^{-1}$ & $\pm 0.1 \%$ \\
$\dot{V}_{\mathrm{cf}}$ & MFM & Yokogawa RXF015G & $0-201 \mathrm{~min}^{-1}$ & $\pm 1 \%$ \\
$T$ & TC & Omega Type T & $20-180^{\circ} \mathrm{C}$ & $\pm 0.19 \mathrm{~K}$ \\
$p$ & PT & Vegabar82 & $1-51 \mathrm{bar}$ & $\pm 0.45 \%$ \\
$\Delta p$ & DPS & Yokogawa EJX110A & $5-400 \mathrm{mbar}$ & $\pm 0.046 \%$ \\
\hline
\end{tabular}

control purposes and data acquisition was carried out with Labview. Thermodynamic calculations were performed in real-time using the CoolProp-Labview wrapper [45].

The preheater HX-A and evaporator HX-B consist of 8 and 10 plates respectively, $76 \mathrm{~mm}$ in width and $317 \mathrm{~mm}$ in length with an herringbone corrugation. In figure 3, a schematic representation of the herringbone-type plate is reported and the main geometric characteristics are listed in Table 2. During the experiments, the preheater HX-A and evaporator HX-B were connected in parallel on the secondary fluid side, and were fed with a varying thermal oil mass flow rate at a constant temperature. The system was considered in steady-state when the oscillations characterizing all the temperature readings exhibited an amplitude lower than $0.5 \mathrm{~K}$ for 120 seconds. Once this condition was reached, all the measures were recorded for 120 seconds and averaged over this time. 


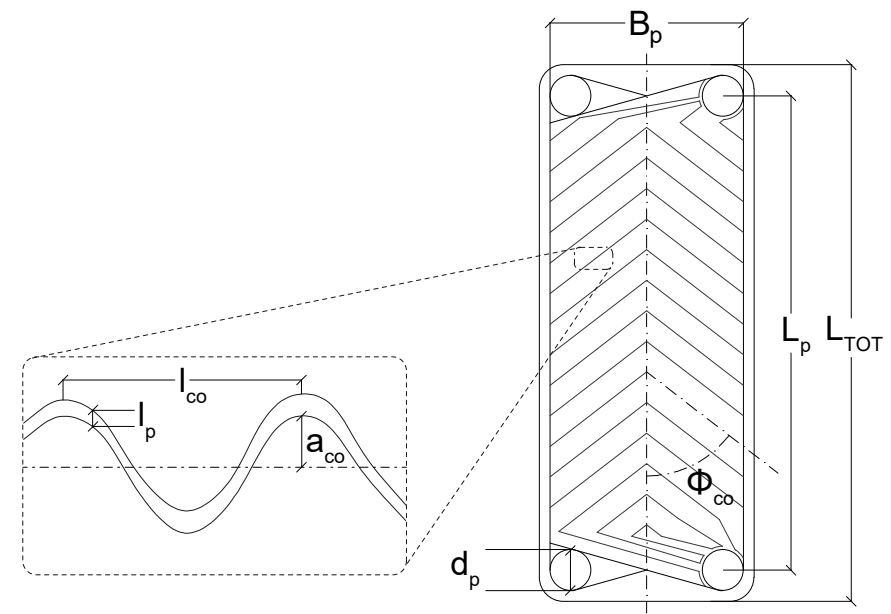

Figure 3: Schematic view of the herringbone-type plate with the relative geometric characteristics.

Table 2: Geometric characteristics of the brazed plate used for the BPHXs.

\begin{tabular}{lcc}
\hline Parameter & Symbol & Value \\
\hline Total length $(\mathrm{mm})$ & $\mathrm{L}_{\mathrm{tot}}$ & 317 \\
Port-to-port length $(\mathrm{mm})$ & $\mathrm{L}_{\mathrm{p}}$ & 278 \\
Plate width $(\mathrm{mm})$ & $\mathrm{B}_{\mathrm{p}}$ & 76 \\
Port diameter $(\mathrm{mm})$ & $\mathrm{d}_{\mathrm{p}}$ & 16 \\
Hydraulic diameter $(\mathrm{mm})$ eq. 1 & $\mathrm{~d}_{\mathrm{h}}$ & 3.4 \\
Plate thickness $(\mathrm{mm})$ & $\mathrm{l}_{\mathrm{p}}$ & 0.3 \\
Wavelength $(\mathrm{mm})$ & $\mathrm{l}_{\mathrm{co}}$ & 7 \\
Corrugation depth $(\mathrm{mm})$ & $\mathrm{a}_{\mathrm{co}}$ & 1 \\
Corrugation type $(-)$ & & Herringbone \\
Corrugation angle $(\mathrm{deg})$ & $\phi_{\mathrm{co}}$ & 65 \\
Area of the plate $\left(\mathrm{m}^{2}\right)$ & $\mathrm{A}_{\mathrm{p}}$ & 0.02329 \\
Wall heat conduction $\left(\mathrm{W} \mathrm{K}^{-1} \mathrm{~m}^{-1}\right)$ & $k_{\mathrm{wall}}$ & 16.2 \\
\hline
\end{tabular}

\section{Data reduction}

In this work, the geometric calculation of the herringbone-type plate heat exchangers are based upon Martin definitions [46]. The hydraulic diameter, $\mathrm{d}_{\mathrm{h}}$ is defined as

$$
d_{\mathrm{h}}=\frac{4 \mathrm{a}_{\mathrm{co}}}{\Phi}
$$

with $\mathrm{a}_{\mathrm{co}}$ the corrugation depth and $\Phi$, the surface enhancement factor, defined as the ratio between the real surface area with respect to the projected area and computed as

$$
\Phi \approx\left(1+\sqrt{1+X^{2}}+4 \cdot \sqrt{1+X^{2} / 2}\right) / 6
$$

where $\mathrm{X}$ is the dimensionless corrugation parameter or wave number defined as

$$
X=\frac{2 \cdot \pi \cdot \mathrm{a}_{\mathrm{co}}}{\mathrm{l}_{\mathrm{co}}}
$$




\subsection{Working fluid-side analysis}

The overall heat transfer coefficient $\mathrm{U}$ was equal to

$$
U=\frac{\dot{Q}}{A_{\mathrm{HX}} \Delta T_{\mathrm{ln}}}
$$

with $A_{\mathrm{HX}}$ the heat transfer area, $\Delta T_{\mathrm{ln}}$ the mean temperature difference and $\dot{Q}$ the thermal power calculated from the oil side of the heat exchanger as

$$
\dot{Q}=\dot{m}_{\text {oil }} \cdot c_{\mathrm{p}, \mathrm{oil}} \cdot \Delta T_{\text {oil }}
$$

The heat transfer area, $A_{\mathrm{HX}}$ was computed as

$$
A_{\mathrm{HX}}=A_{\mathrm{p}} \cdot n_{\mathrm{ch}, \min } \cdot 2
$$

where $n_{\mathrm{ch}, \min }$ was the minimum number of channels between the two HX sides and $A_{\mathrm{p}}$ is the area of one plate calculated as follows

$$
A_{\mathrm{p}}=L_{\mathrm{tot}} \cdot B_{\mathrm{p}}-\pi \cdot d_{\mathrm{p}}^{2}
$$

As the refrigerant passed through the evaporator HX-B in two-phase flow with no phase transition, the logarithmic mean temperature difference was calculated as

$$
\Delta T_{\ln }=\frac{T_{\text {oil,su }}-T_{\text {oil,ex }}}{\ln \left(\frac{T_{\text {oils,su }} T_{\text {sat }}}{T_{\text {oilex }}-T_{\text {sat }}}\right)}
$$

where $T_{\text {sat }}$ was the refrigerant saturation temperature at the evaporating pressure $p_{\mathrm{HXB}, \mathrm{su}}$. The average heat transfer coefficient of the refrigerant in HX-B was then computed as

$$
\alpha_{\mathrm{wf}}=\left(1 / U-R_{\mathrm{wall}}-1 / \alpha_{\mathrm{oil}}\right)^{-1}
$$

where $R_{\text {wall }}$ was the metal wall thermal resistance defined as the ratio of the plate thickness, $l_{\mathrm{p}}$, to the metal thermal conductivity, $k_{\text {wall }}$, computed at the wall average temperature $T_{\text {wall,m }}$ defined as

$$
T_{\text {wall,m }}=\frac{T_{\text {oil,su }}+T_{\text {oil,ex }}+T_{\mathrm{wf}, \mathrm{su}}+T_{\mathrm{wf}, \mathrm{ex}}}{4}
$$

The working fluid vapour quality at the inlet, $X_{\mathrm{HXB}, \mathrm{su}}$, and outlet, $X_{\mathrm{HXB}, \mathrm{ex}}$, of the evaporator HX-B were calculated from the temperature and pressure at the inlet of the preheater HX-A adding the oil thermal power exchanged in HX-A, $\dot{Q}_{\mathrm{HXA}, \mathrm{oil}}$ and HX-B, $\dot{Q}_{\mathrm{HXB}, \text { oil }}$ as follows

$$
\begin{aligned}
X_{\mathrm{HXB}, \mathrm{su}} & =f\left(h_{\mathrm{HXB}, \mathrm{su}}, p_{\mathrm{HXB}, \mathrm{su}}\right) \\
h_{\mathrm{HXB}, \mathrm{su}} & =h_{\mathrm{HXA}, \mathrm{su}}+\frac{\dot{Q}_{\mathrm{HXA}, \mathrm{iil}}}{\dot{m}_{\mathrm{wf}}} \\
X_{\mathrm{HXB}, \mathrm{ex}} & =f\left(h_{\mathrm{HXB}, \mathrm{ex}}, p_{\mathrm{HXB}, \mathrm{ex}}\right) \\
h_{\mathrm{HXB}, \mathrm{ex}} & =h_{\mathrm{HXB}, \mathrm{su}}+\frac{\dot{Q}_{\mathrm{HXB}, \mathrm{iil}}}{\dot{m}_{\mathrm{wf}}}
\end{aligned}
$$

where $f$ indicates the equation of state of the fluid solved through the thermophysical properties library CoolProp [45]. The frictional pressure drop during refrigerant vaporization, $\Delta p_{f}$, was evaluated based on the measured pressure drop subtracting the momentum, $\Delta p_{m o m}$, the gravity, $\Delta p_{g}$ and the manifolds and port, $\Delta p_{m p}$, pressure drops following the guidelines reported in Claesson [22]. As the capillary tubes connecting the evaporator HX-B working fluid inlet and outlet channels to the differential pressure drop sensor were characterized by different elevation, a term accounting for the elevation difference was considered assuming liquid in the capillary tubes (non-insulated). The frictional pressure drop was therefore computed as

$$
\Delta p_{\mathrm{f}}=\Delta p_{\text {meas }}-\Delta p_{\text {mom }}-\Delta p_{\mathrm{g}}-\Delta p_{\mathrm{mp}}+\Delta p_{\mathrm{g}, \mathrm{conn}}
$$


In particular the momentum pressure drop is defined as

$$
\Delta p_{\mathrm{mom}}=G_{\mathrm{wf}}^{2} \cdot\left(\frac{1}{\rho_{\mathrm{tp}, \mathrm{ex}}}-\frac{1}{\rho_{\mathrm{tp}, \mathrm{su}}}\right)
$$

where $G_{\mathrm{wf}}$ is the working fluid mass flux in the HX-B channels and $\rho_{\mathrm{tp}, \mathrm{ex} / \mathrm{su}}$ is the homogeneous two-phase density at the outlet/inlet of HX-B defined as

$$
\rho_{\mathrm{tp}, \mathrm{ex} / \mathrm{su}}=\left(\frac{X_{\mathrm{ex} / \mathrm{su}}}{\rho_{\mathrm{v}}}+\frac{\left(1-X_{\mathrm{ex} / \mathrm{su}}\right)}{\rho_{\mathrm{l}}}\right)^{-1}
$$

The gravity pressure drop is computed by

$$
\Delta p_{\mathrm{g}}=\mathrm{g} \cdot \rho_{\mathrm{m}} \cdot L_{\mathrm{p}}
$$

where $\rho_{\mathrm{m}}$ is the homogeneous average two-phase density:

$$
\rho_{\mathrm{m}}=\left(\frac{X_{\mathrm{m}}}{\rho_{\mathrm{v}}}+\frac{1-X_{\mathrm{m}}}{\rho_{\mathrm{l}}}\right)^{-1}
$$

where $X_{\mathrm{m}}$ is the average quality in HX-B. The manifolds pressure drop is estimated using the port mass flux of HX-B as

$$
\Delta p_{\mathrm{mp}}=1.5 \cdot \frac{G_{\mathrm{wf}, \mathrm{port}}^{2}}{2 \cdot \rho_{\mathrm{m}}}
$$

where $G_{\mathrm{wf}, \text { port }}$ is the mass flux computed at the port cross section of HX-B. The correction due to the different elevation of the connecting lines from the evaporator HX-B to the differential pressure sensor is computed as

$$
\Delta p_{\mathrm{g}, \mathrm{conn}}=g \cdot L_{\mathrm{diff}} \cdot \rho_{\mathrm{l}}
$$

where $L_{\mathrm{diff}}$ is the difference in meter between the two connecting lines. For all the performed calculations, the working fluid, thermal oil and water properties were computed based on the open-source CoolProp library. Incompressibility was assumed for the thermal oil model.

\subsection{Oil-side heat transfer coefficient}

In order to solve equation 9 , the oil side heat transfer coefficient, $\alpha_{\text {oil }}$, is required. A specific oil to water experimental campaign was carried out on heat exchanger $\mathrm{G}$, following the Wilson plot technique, to determine a correlation for the oil heat transfer coefficient. The Wilson plot method allows determining the individual resistances of the heat exchanger to the overall resistance. The original method is subjected to a series of restrictions and several modified approaches have been developed to relax these limitations [42]. In order to minimize the uncertainties of the Wilson plot results the guidelines presented in Sherbini et al. [47] were followed. Two Wilson plot experimental tests were performed by setting two different values of the oil and water temperature at the inlet of HX-G. The tests comprised 15 steady-state points each and the operating conditions are summarized in Table 3. During the experiments the ther-

Table 3: Operating conditions in the heat exchanger HX-G during the two experimental tests for Wilson plot technique.

\begin{tabular}{lcccccc}
\hline Tests & Runs & $\dot{m}_{\text {oil }}\left[\mathrm{kg} \mathrm{s}^{-1}\right]$ & $\mathrm{T}_{\text {oil,su }}\left[{ }^{\circ} \mathrm{C}\right]$ & $\mathrm{T}_{\text {wat,su }}\left[{ }^{\circ} \mathrm{C}\right]$ & $\operatorname{Re}_{\text {oil }}[-]$ & $\operatorname{Pr}_{\text {oil }}[-]$ \\
\hline I & 15 & $0.061-0.119$ & 135 & 20 & $79.5-200$ & $76.27-96.5$ \\
II & 15 & $0.029-0.107$ & 125 & 45 & $30.7-173$ & $78.91-117$ \\
\hline
\end{tabular}

mal energy balance of HX-G was characterized by an error below $4 \%$ for all the recorded data. The thermodynamic properties of the two fluids were determined at the average HX-G fluid temperature. The wall temperature was computed as the average between the inlet and outlet of both fluids and fouling resistances were neglected. The original Wilson plot technique (WPO) and the modified Briggs and Young method (WPBY) were used to identify the oil heat transfer coefficient. The results for the $\langle\mathrm{I}\rangle$ dataset are plotted in Figure 4. The regressions were performed applying 

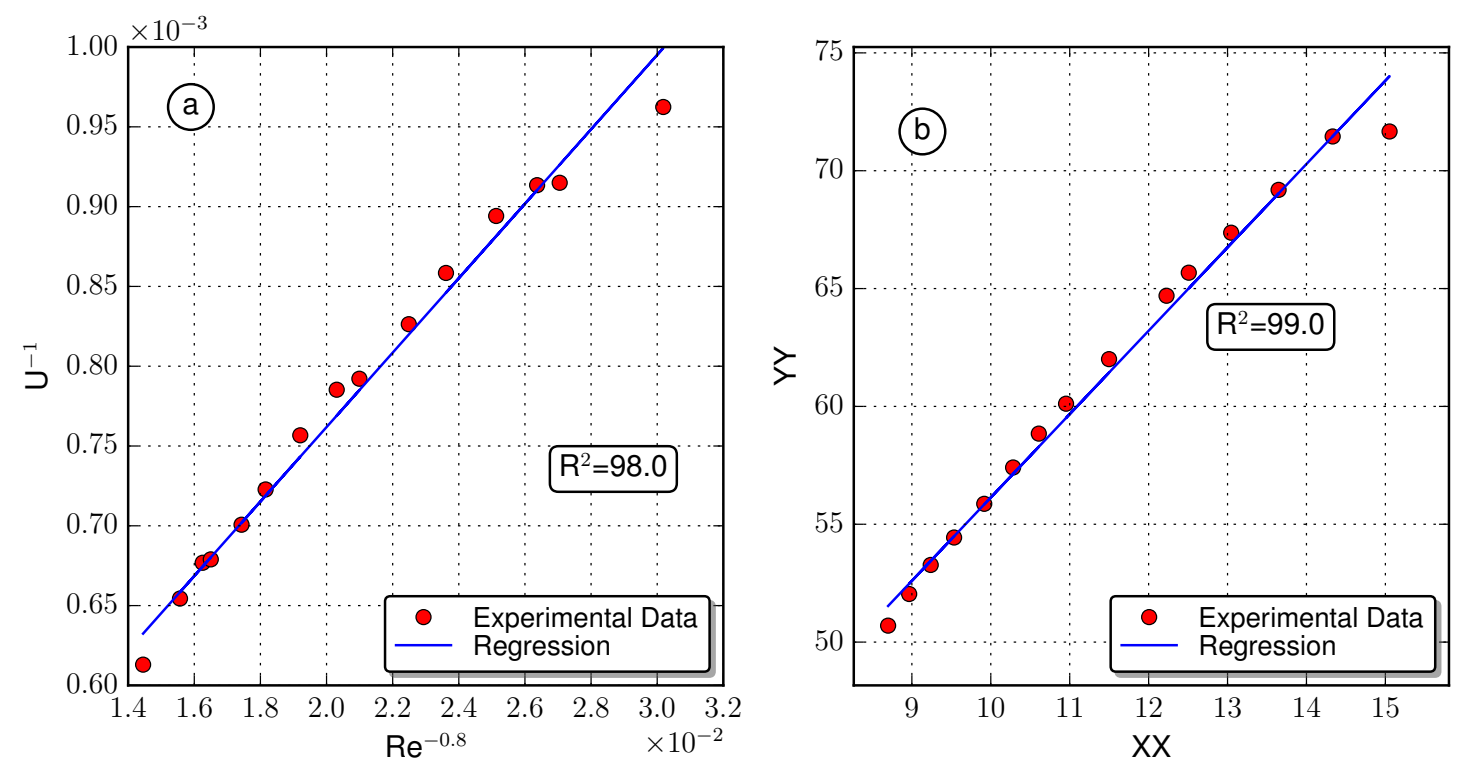

Figure 4: (a) Original Wilson plot (WPO) and (b) modified Briggs and Young Wilson plot (WPBY) results for the $\langle\mathrm{I}\rangle$ dataset of the HX-G experimental campaign. $R^{2}$ : Coefficient of determination.

a least-square error method weighted on the uncertainties of the ordinate data [48]. The co-ordinates of the modified Briggs and Young method shown in Figure $4 \mathrm{~b}$ were defined as

$$
\begin{array}{r}
Y Y=\left[\frac{1}{U}-\frac{t_{\text {wall }}}{k_{\text {wall }}}\right] \cdot\left[\operatorname{Re}_{\text {wat }}^{0.8} \cdot \operatorname{Pr}_{\text {wat }}^{1 / 3} \cdot k_{\text {wat }} / d_{\mathrm{h}}\left(\mu_{\text {wat }} / \mu_{\text {wall,wat }}\right)^{0.14}\right] \\
X X=\frac{\operatorname{Re}_{\text {wat }}^{0.8} \cdot \operatorname{Pr}_{\text {wat }}^{1 / 3} \cdot k_{\text {wat }} / d_{\mathrm{h}}\left(\mu_{\text {wat }} / \mu_{\text {wall,wat }}\right)^{0.14}}{\operatorname{Re}_{\text {oil }}^{0.8} \cdot \operatorname{Pr}_{\text {oil }}^{1 / 3} \cdot k_{\text {oil }} / d_{\mathrm{h}}\left(\mu_{\text {oil }} / \mu_{\text {wall,oil }}\right)^{0.14}}
\end{array}
$$

where all the fluids properties were computed at the average heat exchanger temperature and $d_{h}$ was the hydraulic diameter computed accounting for the surface enhancement factor as defined in Martin [46]. The oil Reynolds exponent resulted from an iterative process as reported in Shah [42]. The slopes of the linear regressions shown in Figure 4 are the constant of the power law-type calibration correlations defining the oil Nusselt number. The coefficients of the four derived calibration equations are reported in Table 4.

Table 4: Constants values for the original Wilson plot (WPO) and the modified Briggs and Young Wilson plot (WPBY).

\begin{tabular}{l|rr|ll}
\hline Tests & $N u_{\mathrm{WPO}}=C_{0} R e^{a}$ & $(24)$ & $N u_{\mathrm{WPBY}}=C_{I} \operatorname{Re}^{a} \operatorname{Pr}^{1 / 3}\left(\mu_{\mathrm{oil}} / \mu_{\mathrm{wall}, \text { oil }}\right)^{0.14}$ \\
\hline $\mathrm{I}$ & $C_{0}=1.13 \pm 0.08$ & $a=0.8$ & $C_{0}=0.283 \pm 0.028$ & $a=0.8$ \\
$\mathrm{II}$ & $C_{0}=1.29 \pm 0.05$ & $a=0.8$ & $C_{0}=0.285 \pm 0.014$ & $a=0.8$ \\
\hline
\end{tabular}

The Wilson plot-based oil Nusselt equations are plotted in Figure 5 against the oil Reynolds number together with existing correlations available in the literature for the conditions of the $\langle\mathrm{II}\rangle$ experimental dataset. For a given oil Reynolds number the Wilson plot-based equations exhibited Nusselt values which were up to two times higher than the one predicted with existing correlations. This can be explained by the fact that the tested single phase correlations were mainly derived from experiments employing water, a fluid characterized by thermophysical properties which significantly differ from those of a thermal oil specifically synthesized to have enhanced heat transfer features. As 


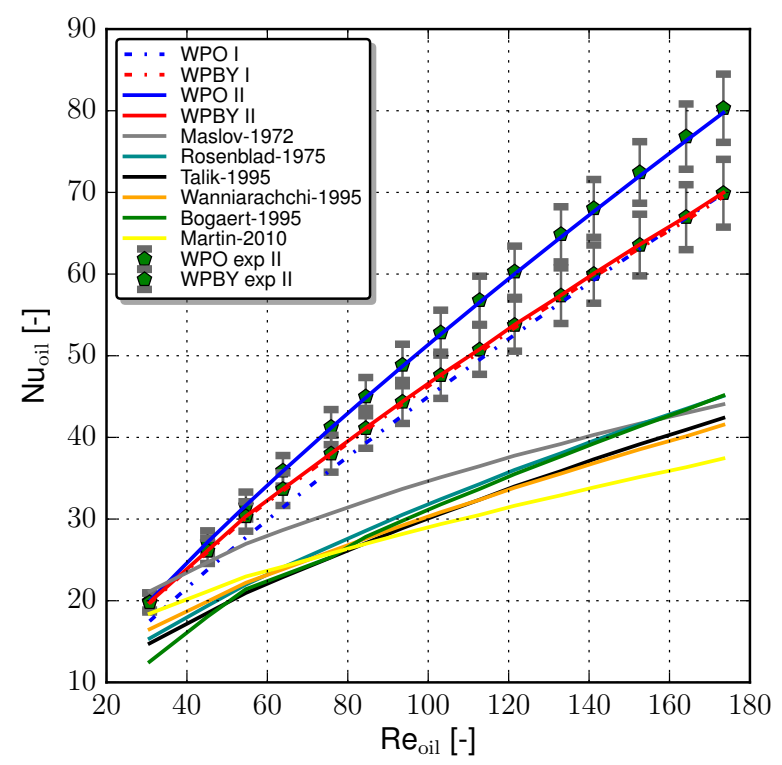

Figure 5: Comparison between the developed Oil Nusselt number equations versus Reynolds number for the developed equations and a number of existing correlation. I and II refer to the two different set of experiments. WPO: original Wilson plot, WPBY: modified Briggs and Young, exp: experimental data. The uncertainties for the experimental Nusselt numbers are derived applying the error propagation theory. The existing correlations have the following sources: Maslov-1972 [49]; Rosenblad-1975 [50]; Talik-1955 [51, 52]; Wanniarachchi-1995 [53]; Bogaert-1995 [54]; Martin-2010 [46].

indicated in Figure 5, the WPO and the WPBY correlations based on the $\langle$ II $\rangle$ dataset were characterized by a diverging trend. This can be explained by modest changes of fluid properties during the tests which are not taken into account in equation 24. As WPBY method allowed to relax this limitation, the correlation derived from the modified Briggs and Young approach was selected for predicting the oil Nusselt number. The final calibrated equation is expressed as

$$
\begin{aligned}
N u= & 0.283 \cdot \operatorname{Re}_{\text {oil }}^{0.8} \cdot \operatorname{Pr}_{\text {oil }}^{\frac{1}{3}} \cdot\left(\mu_{\text {oil }} / \mu_{\text {wall,oil }}\right)^{0.14} \\
& 31.6<\operatorname{Re}<205 \Lambda \quad 76<\operatorname{Pr}<117
\end{aligned}
$$

It is worth mentioning that the validity of Equation 26 is restricted to the specific heat exchanger geometry over the reported range of Reynolds and Prandtl number.

\section{Results and analysis}

A set of 70 and 80 steady-state points have been collected for HFC-245fa and HFO-1233zd respectively at three different saturation temperatures $\left(100^{\circ} \mathrm{C}, 115^{\circ} \mathrm{C}, 130^{\circ} \mathrm{C}\right)$ with varying inlet and outlet vapour conditions and for mass flux varying between 62 and $103.5 \mathrm{~kg} \mathrm{~s}^{-1} \mathrm{~m}^{-2}$. In Table 5 the working conditions are reported for the two fluids. The maximum uncertainty for the main computed variables are reported in Table 6 . The error analysis was done following the guidelines reported by Kline et al. [55] and indicated a maximum uncertainty of 9.5 and $6 \%$ for the working fluid average heat transfer coefficient and the pressure drop respectively.

\subsection{Heat transfer coefficient analysis}

In Figures 6a and 7a, the average heat transfer coefficient, computed based on Equation 9, is plotted versus the average evaporator HX-B quality for HFC-R245fa and HFO-1233zd respectively. For all the analysed conditions the heat transfer coefficients varied between a minimum of around $2800 \mathrm{~W} \mathrm{~m}^{-2} \mathrm{~K}^{-1}$ and a maximum of around $4300 \mathrm{~W}$ $\mathrm{m}^{-2} \mathrm{~K}^{-1}$ for both fluids. In the performed experiments the heat flux and the outlet vapour quality were coupled, i.e. 
Table 5: Operating conditions in the evaporator HX-B during the experimental tests for HFC-245fa and HFO-1233zd.

\begin{tabular}{lccccccc}
\hline Fluid & runs & $\mathrm{p}_{\text {eva }}[\mathrm{bar}]$ & $\mathrm{X}_{\mathrm{su}}$ & $\mathrm{X}_{\mathrm{ex}}$ & $\mathrm{G}_{\mathrm{wf}}\left[\mathrm{kg} \mathrm{s}^{-1} \mathrm{~m}^{-2}\right]$ & $\mathrm{G}_{\text {oil }}\left[\mathrm{kg} \mathrm{s}^{-1} \mathrm{~m}^{-2}\right]$ & $\dot{q}\left[\mathrm{~kW} \mathrm{~m}^{-2}\right]$ \\
\hline HFC-245fa & 70 & $12.51-23.85$ & $0.05-0.39$ & $0.48-1$ & $62.8-103.5$ & $72.7-136.6$ & $13-36$ \\
HFO-1233zd & 80 & $10.33-19.35$ & $0.14-0.39$ & $0.53-1$ & $62.0-102.8$ & $51.3-149.7$ & $9-37$ \\
\hline
\end{tabular}

Table 6: Maximum uncertainty of the main calculated variables for the evaporator HX-B.

\begin{tabular}{lc}
\hline Variables & Maximum uncertainty $(\mathrm{k}=2)$ \\
\hline Area HX-B & $\pm 0.0028 \mathrm{~m}^{2}$ \\
LMTD HX-B & $\pm 1.4 \%$ \\
Heat flux & $\pm 4 \%$ \\
Refrigerant mass flux & $\pm 2.5 \%$ \\
Average vapour quality & $\pm 5 \%$ \\
Overall heat transfer coefficient & $\pm 3.5 \%$ \\
Refrigerant heat transfer coefficient & $\pm 9.5 \%$ \\
Frictional pressure drop & $\pm 11.6 \%$ \\
\hline
\end{tabular}

in order to increase/decrease the evaporator HX-B outlet vapour quality the heat flux was increased/decreased. It was therefore not possible to clearly identify the effects of the two parameters on the heat transfer coefficient trend. In Figure $6 \mathrm{~b}$ and $7 \mathrm{~b}$ the average heat transfer coefficients at a saturation temperature of $115^{\circ} \mathrm{C}$ for different mass fluxes is plotted versus the average evaporator HX-B quality for HFC-245fa and HFO-1233zd. As the mass flux increased, the heat transfer coefficients slightly increased. The effect was stronger for HFC-245fa than for HFO-1233zd, but in both cases within the maximum uncertainty. Thus for both fluids a weak sensitivity of the heat transfer coefficients with respect to the mass flux was found. In Figure $6 \mathrm{c}$ and $7 \mathrm{c}$ the average heat transfer coefficients at a mass flux of $100 \mathrm{~kg} \mathrm{~m}^{-2} \mathrm{~s}^{-1}$ for different saturation temperatures is plotted versus the average evaporator HX-B quality for HFC245fa and HFO-1233zd. The heat transfer coefficient values were characterized by an increasing trend as the mean vapour quality increased up to a certain value where they experienced a decrease. At low mean quality the convective and nucleate boiling phenomena are expected to co-exist. As the heat flux and quality increases both phenomena are enhanced and this could explain the increasing trend [56]. The decrease of the heat transfer coefficients at around $X_{\mathrm{m}}=0.5-0.6$ could be related to local occurrence of dry-out in accordance with Shiferaw et al. [57] and Copetti et al. [58]. This effect was stronger for HFC-245fa than for HFO-1233zd. A weak sensitivity to saturation temperature was found in accordance with Longo [35] for both fluids. 

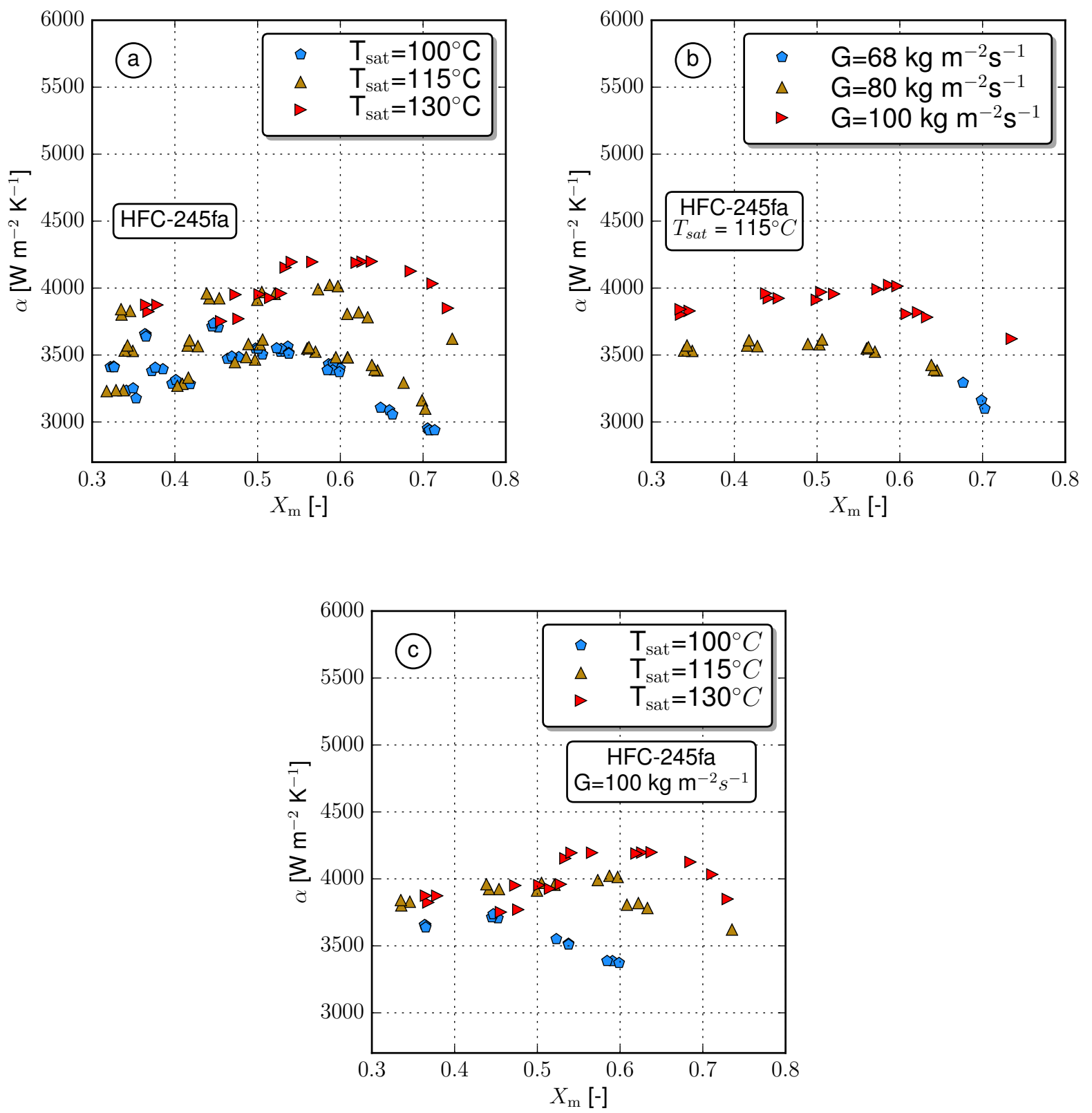

Figure 6: (a) HFC-245fa average heat transfer coefficient versus mean quality (b) Mass flux dependence of HFC-245fa average heat transfer coefficient for $T_{\mathrm{sat}}=115^{\circ} \mathrm{C}$. (c) Saturation temperature dependence of HFC-245fa average heat transfer coefficient for $\mathrm{G}=100 \mathrm{~kg} \cdot \mathrm{m}^{-2} \mathrm{~s}^{-1}$ 

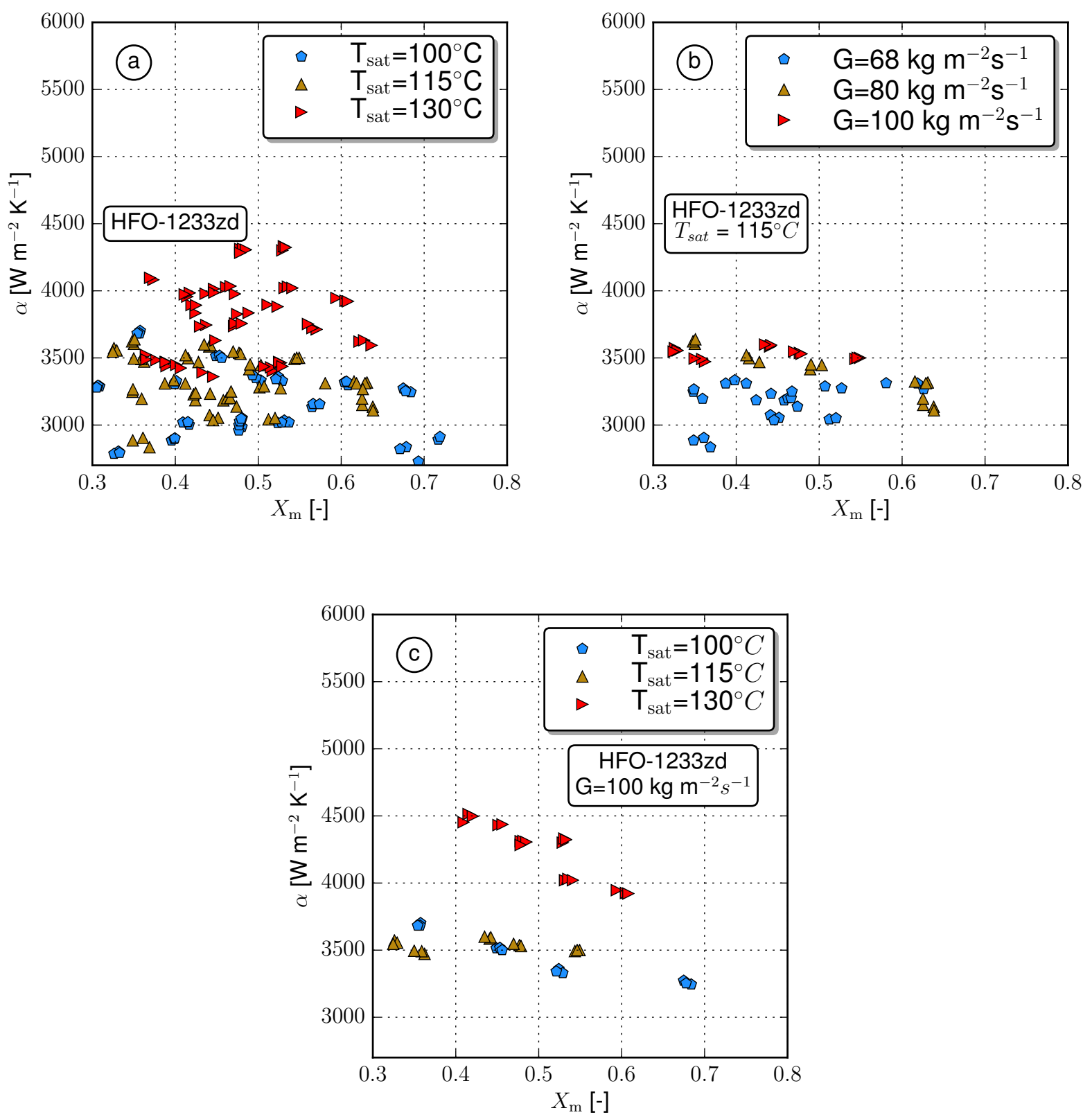

Figure 7: (a) HFO-1233zd average heat transfer coefficient versus mean quality (b) Mass flux dependence of HFO-1233zd average heat transfer coefficient for $T_{\mathrm{sat}}=115^{\circ} \mathrm{C}$ (c) Saturation temperature dependence of HFO-1233zd average heat transfer coefficient for G=100 kg $\mathrm{m}^{-2} \mathrm{~s}^{-1}$

In order to investigate the dominant heat transfer regime during vaporization the criterion proposed by Thonon et al. [26] was applied. It is based on the product of the Boiling number, Bo, and the Lockart-Martinelli parameter, $X_{t t}$, and it is expressed as

$$
\begin{aligned}
B o X_{\mathrm{tt}} & >0.15 \cdot 10 e^{-3} \quad \text { Nucleate boiling regime } \\
\text { Bo } X_{\mathrm{tt}} & <0.15 \cdot 10 e^{-3} \quad \text { Convective boiling regime }
\end{aligned}
$$




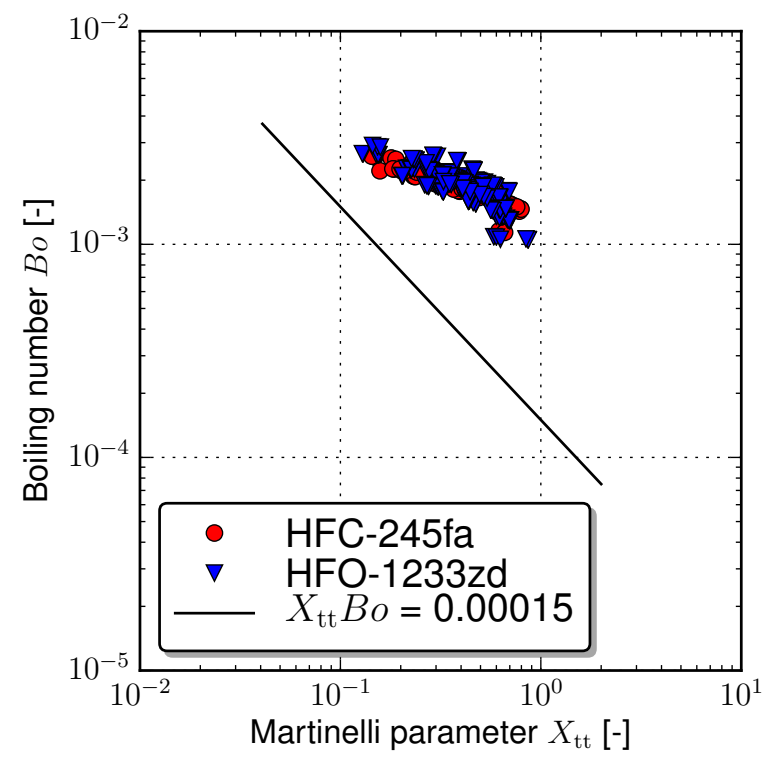

Figure 8: Thonon et al. criterion [26] to investigate the heat transfer regime for R245fa and R1233ZD.

where $B o$ and $X_{t t}$ are defined as follows

$$
\begin{array}{r}
B o=\frac{\dot{q}_{\mathrm{HXB}}}{G_{\mathrm{wf}} \cdot \Delta h_{\mathrm{vap}}} \\
X_{\mathrm{tt}}=\left(\frac{\left(1-X_{\mathrm{m}}\right.}{X_{\mathrm{m}}}\right)^{0.9} \cdot\left(\frac{\rho_{\mathrm{v}}}{\rho_{\mathrm{l}}}\right)^{0.5} \cdot\left(\frac{\mu_{\mathrm{l}}}{\mu_{\mathrm{v}}}\right)^{0.1}
\end{array}
$$

The results, reported in Figure 8 for both fluids, indicate the nucleate boiling as the leading phenomena for all the measured steady-state points for HFC-245fa and HFO-1233zd. These results should be taken as indicative only, as the method does not account for the effects of heat exchanger geometrical parameters [26]. 


\subsection{Two-phase pressure drop analysis}

The frictional pressure drop values, calculated based on Equation 15, are plotted versus the average quality in the evaporator HX-B in Figure 9 for HFC-245fa and HFO-1233zd. The values are comparable for the two fluids ranging from a few kPa.m $\mathrm{m}^{-1}$ to a maximum of around $45 \mathrm{kPa} \cdot \mathrm{m}^{-1}$. In Figures 10a-b the frictional pressure drop for a mass flux of $100 \mathrm{~kg} \cdot \mathrm{m}^{-2} \mathrm{~s}^{-1}$ is plotted versus the average quality in the evaporator HX-B for the two fluids. The results indicate that the pressure drop increases monotonically with the average quality in accordance with the data recorded by Yan et al. [27] and by Copetti et al. [58] for HFC-134a. This can be explained by an increase of the vapour mass velocity as the quality rises. Furthermore, the results suggest the higher the saturation temperature the lower the pressure drop. This trend results from the change of thermo-physical properties, density and viscosity, with respect to the saturation temperature. In particular as pressure increases, the vapour becomes more dense leading to lower fluid velocity and pressure drop.
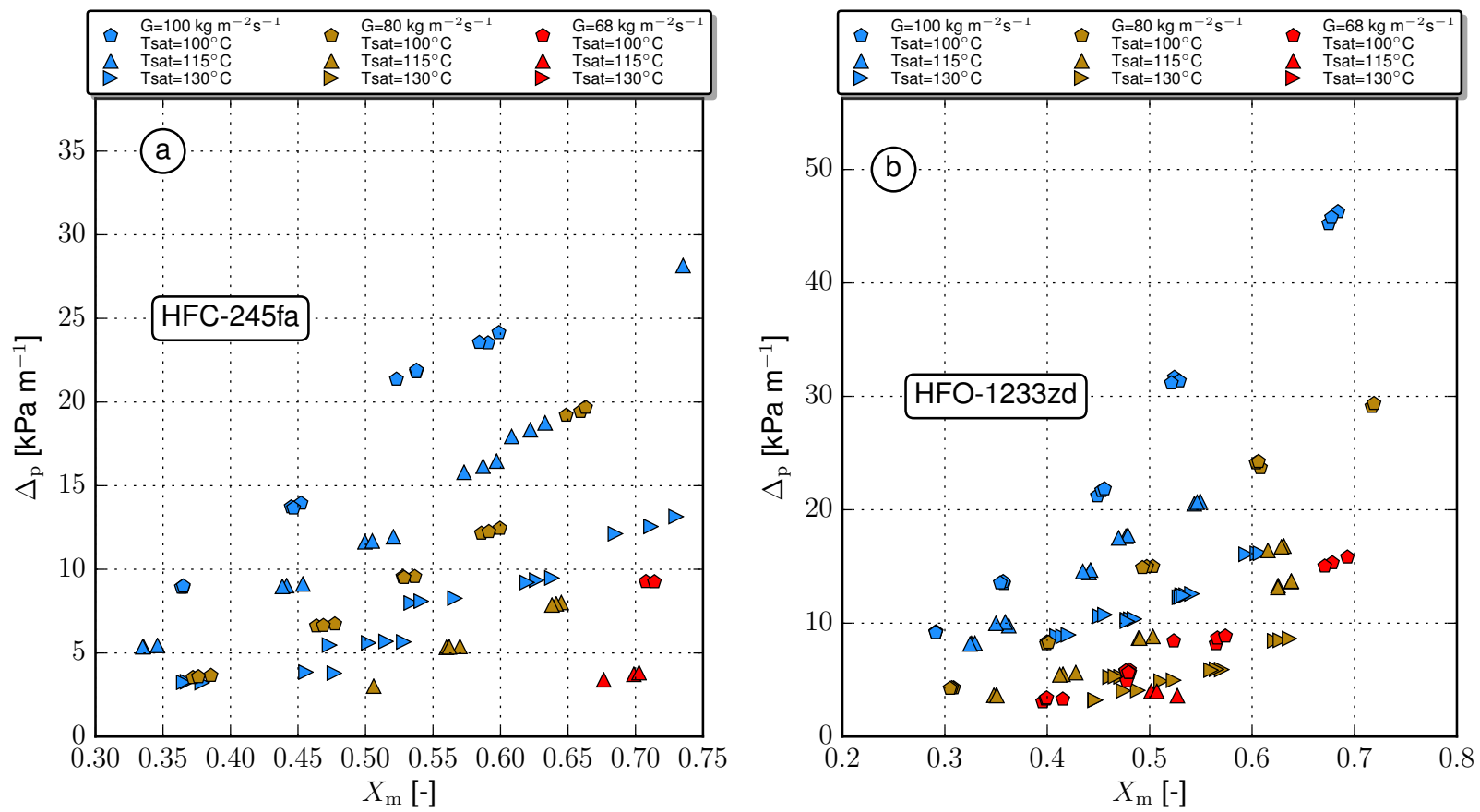

Figure 9: Pressure drop for HFC-245fa and HFO-1233zd versus average quality in the evaporator HX-B for all the measured data. 

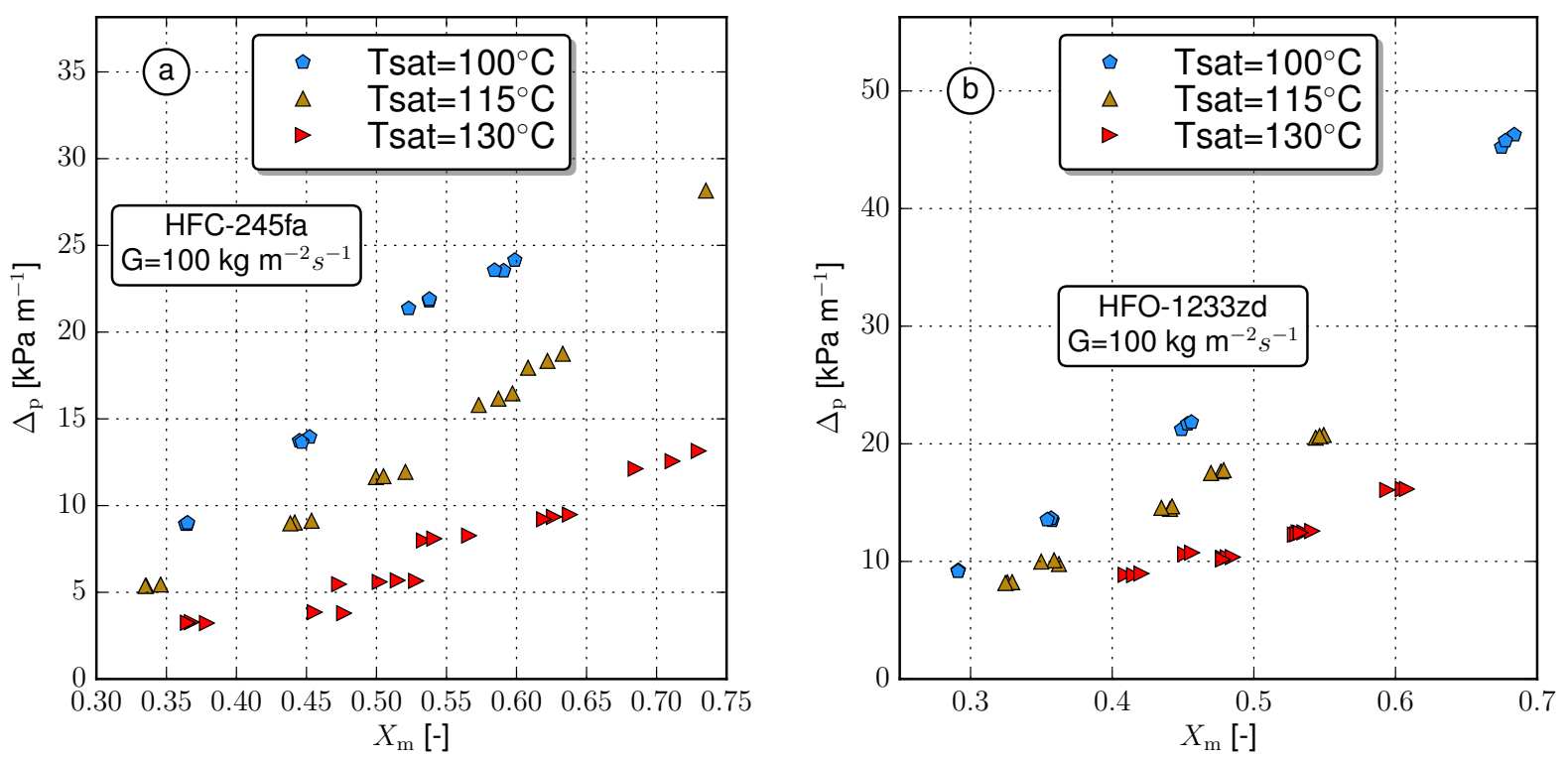

Figure 10: Frictional pressure drop versus average evaporator HX-B quality for a mass flux of $100 \mathrm{~kg} \mathrm{~m}^{-2} \mathrm{~s}^{-1}$ for (a) HFC-245fa and (b) HFO$1233 z d$.

\subsection{Comparison with prediction methods}

A variety of correlations for two-phase heat transfer coefficient and frictional pressure drop have been derived over the years for in-tube flow boiling, pool boiling as well as flow boiling inside plate heat exchangers. In what follows, existing correlations are compared against the experimental heat transfer coefficient and frictional pressure drop measured in this study. As far as two-phase heat transfer coefficient is concerned, three main methods have been developed in the past, namely the superposition, the asymptotic and the enhancement approaches [23]. In this study, the superposition method adopted by Gungor and Winterton [59] is selected for further analysis as it is based on a large database of refrigerants and organic fluids experimental data, although it was derived for intube flow boiling. In their study they found that the Shah enhancement-based model [60] produced the second best results besides their own formulation. For this reason the Shah correlation is also chosen for comparison. As the Thonon criterion results suggested that nucleate boiling was predominant during the experiments (see Figure 8), the Cooper equation [61] and the Gorenflo equation [34] are also selected, even though developed for nucleate pool boiling. The two latter correlations showed good agreement for refrigerant evaporation inside BPHXs at low evaporating temperature in the study presented by Palm et al. [31] and Longo et al. [33]. In recent years, several correlations based on flow boiling experiments with plate heat exchangers have been derived. Among those the Han [30] and Amalfi [41] correlations have been selected. The first is largely used in the refrigeration field as they were among the first to include the effect of the plate geometry [62]. The latter is derived with a dimensional analysis coupled with a multiple regression approach (DACMR) on a large number of published experimental data from thirteen sources related to vaporization of refrigerants in plate heat exchangers.

As far as two-phase frictional pressure drop is concerned, four correlations based on the Fanning friction factor model are selected for comparison against the experimental results. The Ayub correlation [63] derived from experimental data from a large variety of commercial plate heat exchangers in operation between 1992 and 2001 with HFC-22 and ammonia as working fluid is selected. The Amalfi [21] correlation based on a large database of experimental data including different refrigerants is chosen. Amalfi [21] compared different two-phase friction pressure drop correlations against a large database and found that the Khan [36] correlation gave the second best results. For this reason this correlation is also selected. Finally the recently developed Vakili-Farahani [64] correlation valid for 
HFC-245fa at low evaporating temperature is chosen. The characteristics of the selected correlations for heat transfer coefficient and frictional pressure drop prediction are summarized in Table 7 and 8.

Table 7: Summary of models for vaporization heat transfer coefficient. $\beta$ : chevron angle. $\mathrm{d}_{\mathrm{h}}$ : hydraulic diameter

\begin{tabular}{|c|c|c|c|c|}
\hline Investigators & Year & Geometry & Fluids & Characteristics \\
\hline Shah [60] & 1982 & Pipe & $\begin{array}{l}\text { Water,R-11,R-12,R- } \\
\text { 113,Cyclohexane }\end{array}$ & $\begin{array}{l}\text { Enhancement } \\
\text { method; } \mathrm{x}=0.1- \\
1 ; \mathrm{d}=2.9-64.5 \mathrm{~mm}\end{array}$ \\
\hline Cooper [61] & 1984 & Pipe & Water & $\begin{array}{l}\text { Nucleate boiling, } 250 \\
\text { points from } 5 \text { sources, } \\
\mathrm{p}=0.25-71 \text { bar, } \\
\mathrm{d}_{\mathrm{h}}=5-32 \mathrm{~mm} \dot{q}=0.3-15 \\
k W m^{-2}\end{array}$ \\
\hline Gungor-Winterton [59] & 1986 & Pipe & $\begin{array}{l}\text { Water,Refrigerants, } \\
\text { Ethylene-Glycol }\end{array}$ & $\begin{array}{l}\text { Superposition, } 3693 \\
\text { saturated boiling data } \\
\text { from } 29 \text { studies }\end{array}$ \\
\hline Gorenflo [34] & 1988 & Pipe & $\begin{array}{l}\text { Refrigerants, Cryo- } \\
\text { genics, Hydrocarbon }\end{array}$ & Nucleate pool boiling \\
\hline Han et al. [30] & 2003 & PHX & HFC-410A,HFC-22 & $\begin{array}{l}\text { Homogeneous flow } \\
\text { model, } \quad \beta=45^{\circ}-55^{\circ} \text { - } \\
70^{\circ}, \mathrm{T}_{\mathrm{sat}}=5-10-15^{\circ} \mathrm{C}\end{array}$ \\
\hline Amalfi et al. [41] & 2015 & PHX & $\begin{array}{l}\text { Refrigerants, } \\
\text { Ammonia }\end{array}$ & $\begin{array}{l}\text { DACMR method; } \\
1930 \text { experimental } \\
\text { data from } 13 \text { studies }\end{array}$ \\
\hline
\end{tabular}

In order to assess the capability of the selected correlations to predict the experimental data derived in this work, the percentage mean absolute error, $\theta$, was computed as follows

$$
\theta=\frac{1}{n} \cdot \sum_{i=1}^{n} \frac{\left|Y_{\text {exp }, \mathrm{i}}-Y_{\text {pred,i }}\right|}{Y_{\text {exp }, \mathrm{i}}}
$$

where $n$ is the total number of available data, and $Y_{\text {exp,i }}$ and $Y_{\text {pred,i }}$ are the i-th experimental and predicted values respectively. In Figure 11 the selected heat transfer coefficient prediction methods are graphically compared against the recorded experimental data. The results suggest that Shah [60] and Gungor-Winterton [59] correlations exhibit a trend which drastically differ with the experimental data and are characterized by a $\theta$ of around $60 \%$. The prediction methods proposed by Han et al. [30] and Amalfi et al. [21] allow for a slightly better forcast of the experimental data and are characterized by a $\theta$ value of around $50 \%$ and $37 \%$ respectively. It is interesting to notice how the Cooper [61] correlations is able to predict the results with a much smaller error compared to the Gorenflo correlation [34], although both have been developed for nucleate pool boiling phenomena. It is worth noticing that, despite the low mean absolute error, the trend predicted by the Cooper correlation does not match with the experimental data.

The parity plots comparing the selected frictional pressure drop prediction methods against the experimental data are reported in Figure 12. The results suggest that all the selected methods significantly over-predict the pressure drop and present an extremely high percentage mean absolute error. This can be explained by the much lower evaporating temperature characterizing the experimental data on which the selected method were based. As the two-phase frictional pressure drop are inversely proportional to the saturation temperature, the data measured in this study were characterized by much lower values than those predicted with published correlations that are mostly based on low saturation temperatures as shown in Table 8. 
Table 8: Summary of models for two-phase friction pressure drop.

\begin{tabular}{|c|c|c|c|c|}
\hline Investigators & Year & Geometry & Fluids & Characteristics \\
\hline Ayub [63] & 2003 & PHX & Ammonia, HFC-22 & $\begin{array}{l}\beta=30-65^{\circ}, \mathrm{T}_{\text {sat }}=-35 \text { to } \\
5^{\circ} \mathrm{C}\end{array}$ \\
\hline Khan et al. [36] & 2012 & PHX & Ammonia & $\begin{array}{l}\beta=60^{\circ}, \quad \mathrm{d}_{\mathrm{h}}=3.9 \mathrm{~mm}, \\
T_{\text {sat }}=-2 \text { to }-25^{\circ} \mathrm{C}, \dot{q}=21 \\
\text { to } 44 \mathrm{~kW} \mathrm{~m}^{-2}\end{array}$ \\
\hline Vakili-Farahani [64] & 2014 & PHX & HFC-245fa & $\begin{array}{l}\beta=65^{\circ}, \mathrm{T}_{\text {sat }}=19 \text { to } \\
35^{\circ} \mathrm{C}, \quad \mathrm{x}=0.05-0.8, \\
\mathrm{G}=10-40 \mathrm{~kg} \mathrm{~m}^{-2} \mathrm{~s}^{-1}\end{array}$ \\
\hline Amalfi et al. [41] & 2015 & PHX & $\begin{array}{l}\text { Refrigerants, } \\
\text { Ammonia }\end{array}$ & $\begin{array}{l}\text { Refrigerants: } \mathrm{T}_{\text {sat }}=-3 \\
\text { to } 35^{\circ} \mathrm{C} \text {, Water: } \mathrm{T}_{\text {sat }}= \\
20 \text { to } 105^{\circ} \mathrm{C}, 1501 \text { ex- } \\
\text { perimental data from } 13 \\
\text { studies }\end{array}$ \\
\hline
\end{tabular}



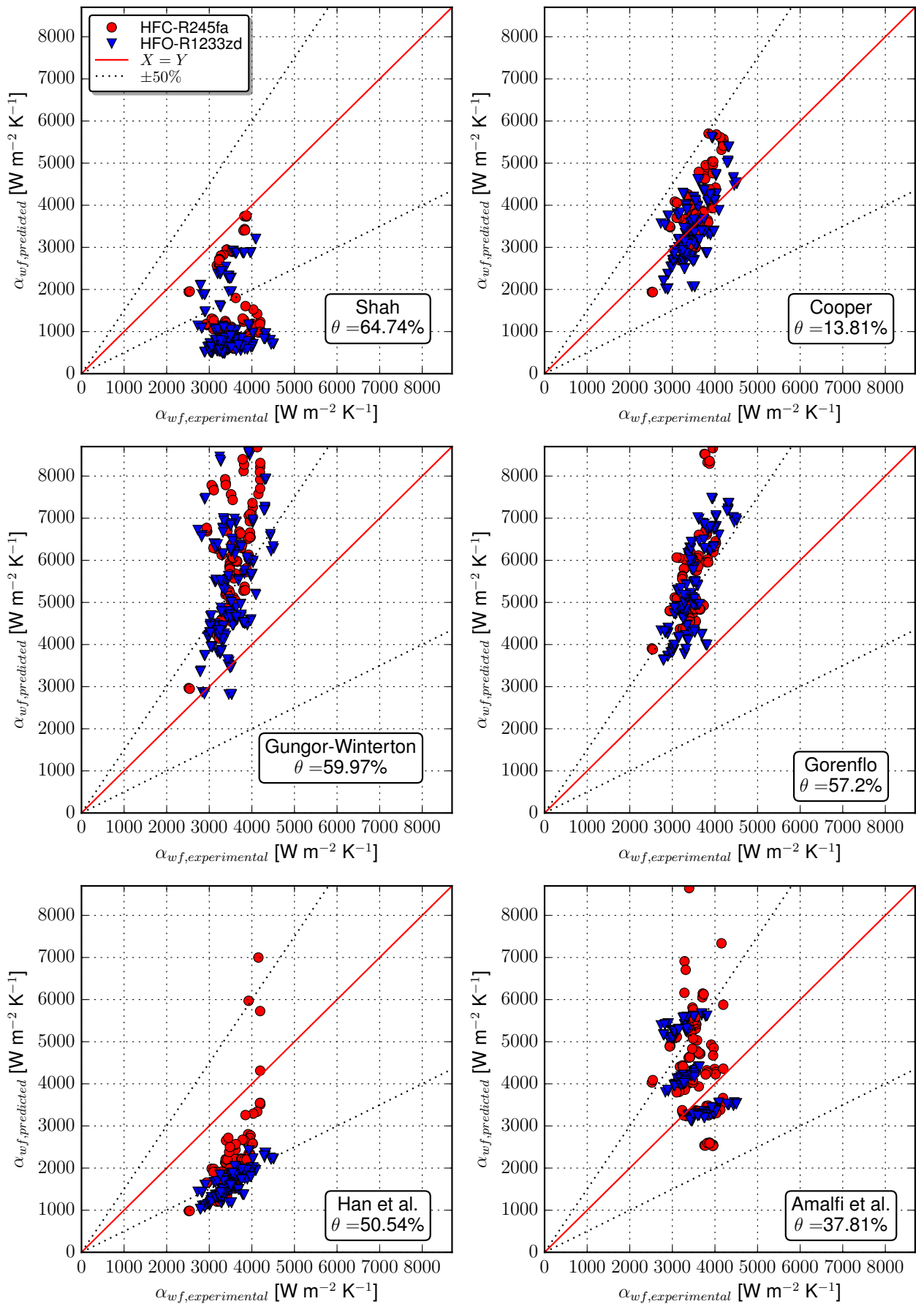

Figure 11: Heat transfer coefficient parity plot between the selected prediction methods and the experimental data for HFC-245fa and HFO-1233zd. The sources for the correlations are the following: Shah [60]; Cooper [61]; Gungor-Winterton [59]; Gorenflo [34]; Han et al. [30]; Amalfi et al. [21] 

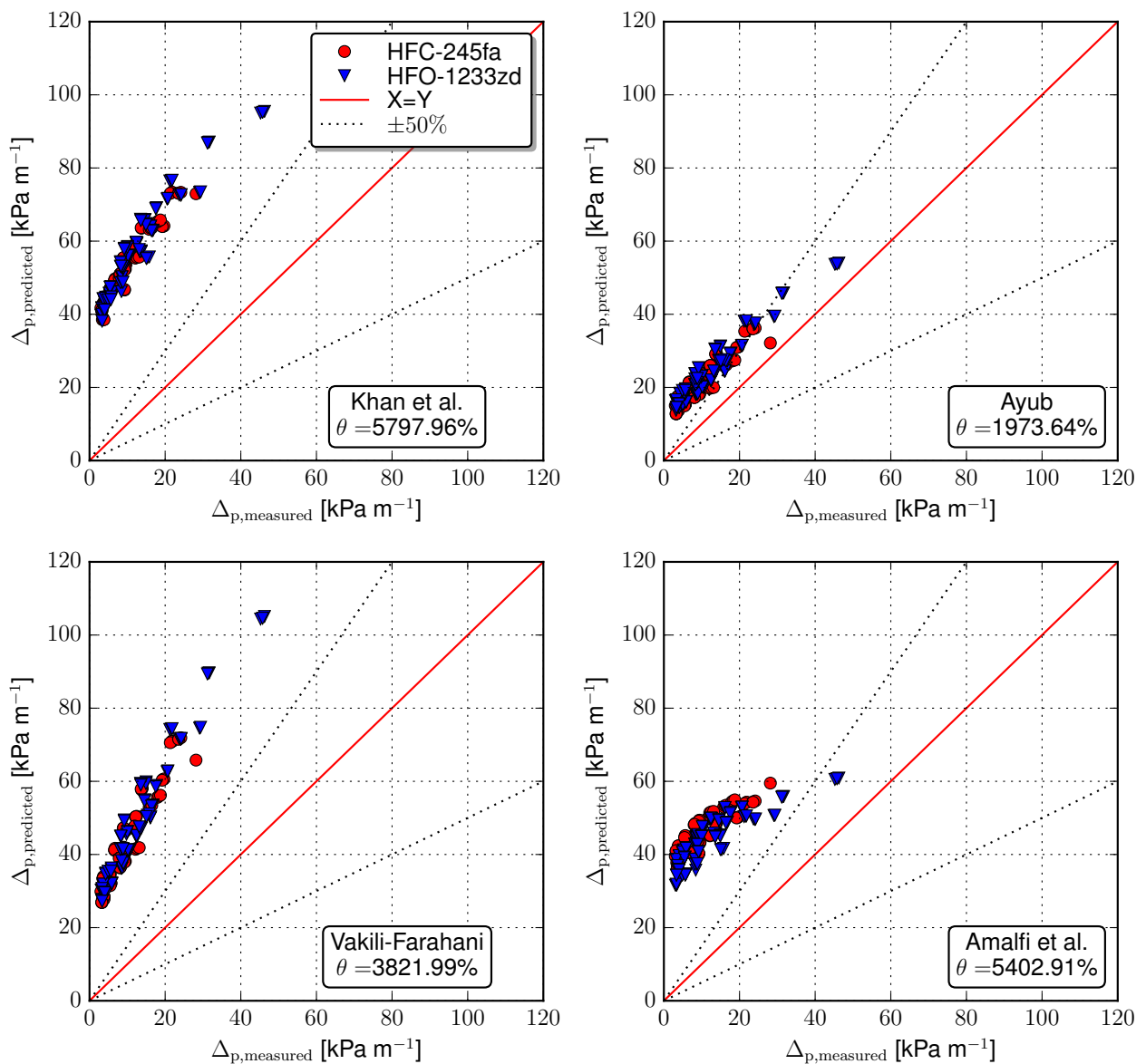

Figure 12: Two-phase frictional pressure drop parity plot between the selected prediction methods and the experimental data for HFC-245fa and HFO-1233zd. The sources for the correlations are the following: Khan et al. [36]; Ayub [63]; Vakili-Farhani et al. [64]; Amalfi et al. [21]. 


\subsection{Two-phase heat transfer and frictional pressure drop prediction methods}

Given the poor agreement of most of the tested heat transfer and frictional pressure drop correlations with respect to the experimental data, new correlations were derived. The main goal was to derive simple but precise law that can be easily implemented in a dynamic model of a heat exchanger to investigate the dynamic trend of such a component. As far as the heat transfer coefficient is concerned, a similar prediction method to the one proposed by Amalfi et al. [21] was employed. The method consists of three subsequent steps. First the independent variables affecting the heat transfer coefficient are defined as reported below

$$
\alpha=f\left(d_{\mathrm{h}}, k_{l}, c_{\mathrm{pl}}, \rho_{\mathrm{l}}, \rho_{\mathrm{v}}, \rho_{\mathrm{m}}, u_{\mathrm{l}}, u_{\mathrm{v}}, u_{\mathrm{m}},\left(\rho_{\mathrm{l}}-\rho_{\mathrm{v}}\right) \cdot g, \mu_{\mathrm{l}}, \mu_{\mathrm{v}}, \dot{q}, \sigma, \Delta h_{\mathrm{vap}}\right)
$$

where $\sigma$ is the surface tension, $\Delta h_{\text {vap }}$ is the latent heat of vaporization, $u_{1 / \mathrm{v} / \mathrm{m}}$ are the saturated liquid, vapour and mean velocity respectively and $\left(\rho_{1}-\rho_{\mathrm{v}}\right) \cdot g$ accounts for the buoyancy force. A non dimensional analysis is then performed to express Equation 32 in a dimensionless form. By arithmetic manipulation the following non-dimensional groups are obtained

$$
\begin{aligned}
\alpha & =\left(W e, R e_{1}, R e_{\mathrm{v}}, B o, B d, \rho^{\star}\right) \\
W e & =\frac{G^{2} \cdot d_{\mathrm{h}}}{\rho_{m} \theta} \\
B o & =\frac{\dot{q}}{G \Delta h_{\mathrm{vap}}} \\
B d & =\frac{\left(\rho_{1}-\rho_{\mathrm{v}}\right) \cdot g \cdot d_{\mathrm{h}}^{2}}{\theta}
\end{aligned}
$$

where $\rho^{\star}$ is the ratio of saturated liquid to vapour density, We is the Weber number which accounts for the inertia forces with respect to the tension forces, $B o$ is the boiling number, accounting for the effect of the heat flux, the mass flux and the latent heat, and $B d$ is the Bond number which characterizes the bubble behaviour in the BPHX. Each non-dimensional group was used to fit the experimental data using a power law. Based on the fitting results, the non-dimensional groups exhibiting the lowest mean absolute error were selected and the ones adding limited gain in accuracy were discarded for the sake of conciseness and simplicity. Following this approach, the two-phase heat transfer coefficient could be predicted as follows

$$
\alpha_{\text {pred }}=1.48 e 3 \cdot W e^{-3.22 e-2} \cdot \rho^{\star-3.38 e-1} \cdot R e_{1}^{4.51 e-1} \cdot B d^{-4.69 e-1}
$$

The correlation allowed predicting the experimental data with a coefficient of determination, $R^{2}$, of $77 \%$ and a mean absolute error $\theta=4.17 \%$ employing four non-dimensional numbers. It is graphically compared against the experimental data in Figure 13a.

As far as frictional pressure drops are concerned, a different approach was employed. As shown by Longo [35], the frictional pressure drop in brazed plate heat exchanger shows a linear dependence with the kinetic energy per unit volume of refrigerant flow and so a quadratic dependence on the refrigerant mass flux

$$
\frac{K E}{V}=\frac{1}{A^{2}} \cdot \frac{\dot{m}^{2}}{2 \cdot \rho_{\mathrm{m}}}
$$

where $K E$ is the kinetic energy and $A$ is a parameter experimentally identified. The parameter $A$ was identified by linear regression and the results are graphically compared against the experimental data in Figure 13b. The correlation was characterized by a coefficient of determination, $R^{2}$, of $74 \%$ and a mean absolute error $\theta=29.78 \%$. The error is quite large, but, given the simplicity of the correlation, it can be considered satisfactory for dynamic modelling of brazed plate heat exchangers where the modeller needs to find a compromise between accuracy and computational speed as shown in [65]. The obtained frictional pressure drop correlation is

$$
\Delta p_{\text {fric }}=138 \cdot \frac{G^{2}}{2 \cdot \rho_{\mathrm{m}}}
$$



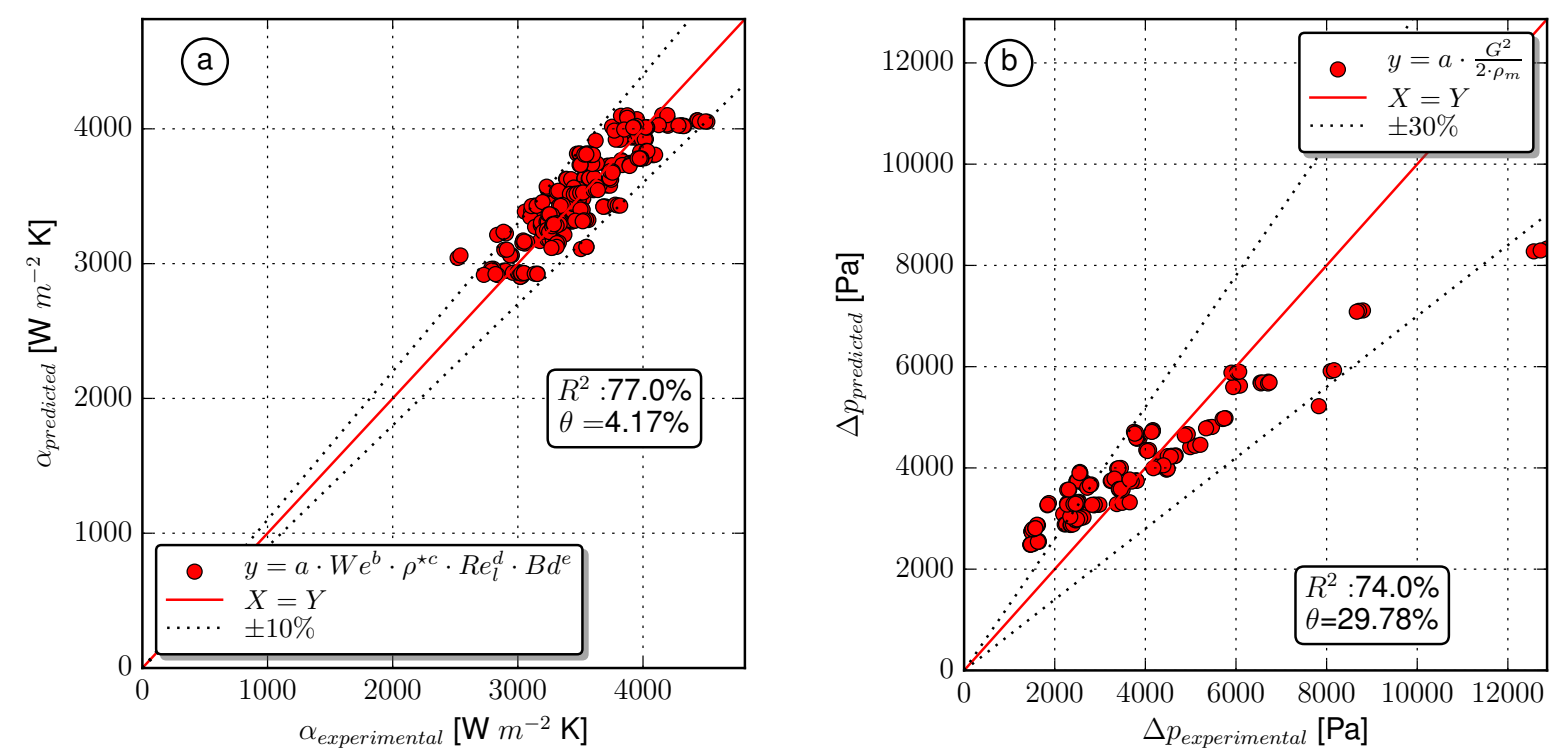

Figure 13: (a) Predicted vaporization heat transfer coefficient versus the experimental data for HFC-245fa and HFO-1233zd (b) Predicted two-phase frictional pressure drop versus the experimental data for HFC-245fa and HFO-1233zd .

\section{Conclusions}

In this paper, an experimental investigation of the vaporization phenomena characterizing HFC-245fa and HFO$1233 z d$ low critical temperature organic fluids in a brazed plate heat exchanger at typical evaporating conditions for ORC power systems has been presented. The experimental results were reported in terms of average working fluid heat transfer coefficient and frictional pressure drop. The effects of saturation temperature, mass flux, inlet and outlet quality conditions on heat transfer and pressure drop during vaporization inside BPHX were analysed. In particular the fluids were tested at saturation temperatures of 100,115 and $130^{\circ} \mathrm{C}$, mass fluxes of $62-102 \mathrm{~kg} \mathrm{~m}^{-2} \mathrm{~s}^{-1}$, heat fluxes of $9-37 \mathrm{~kW} \mathrm{~m}^{-2}$ and outlet vapour qualities of $0.5-1$. The main experimental findings are reported as follows:

- The Wilson plot method was used to derive the thermal oil single phase heat transfer coefficient. It was experimentally demonstrated how the modified Briggs and Young Wilson plot method [66] allows deriving more reliable results than the original Wilson plot approach as it takes into account the thermophysical properties variations of the tested fluids.

- The heat transfer coefficient values were characterized by an increasing trend as the evaporator HX-B mean vapour quality increased up to a certain value where they experienced a decrease. A possible explanation of the decreasing trend starting from a mean quality, $X_{\mathrm{m}}$, of 0.55-0.6 was given by local occurrence of dry-out in accordance with Shiferaw et al. [57] and Copetti et al. [58]. Furthermore weak sensitivity to the saturation temperature and to mass flux was found in agreement with Longo [35], and contrary to the results presented in Shiferaw et al. [57]. These results indicate that nucleate boiling may not be the dominant heat transfer mechanism.

- The frictional pressure drop was found to increase linearly with the increase of vapour quality in accordance with Yan et al. [27] and Copetti et al. [58]. The experimental data clearly showed the inverse proportionality of frictional pressure drop and saturation temperature.

- The average heat transfer coefficients and the two-phase frictional pressure drop were found to be of comparable magnitude for the two fluids. This would allow to replace HFC-245fa with HFO-1233zd in existent ORC power systems without experiencing major variation in the heat exchangers performances. 
- The Thonon method [26] was applied to identify the leading heat transfer mechanism during the vaporization of the two fluids. The results indicate that the nucleate boiling process was predominant in all the recorded data in accordance with Longo [33, 35]. This result has to be considered as indicative only, as the Thonon method was developed without taking into account the geometrical parameters of the heat exchanger.

- Six two-phase average heat transfer coefficient correlations available in the literature were tested to predict the measured experimental data for HFC-245fa and HFO-1233zd. For the tested conditions, only the Cooper correlation [61] was found to be able to reproduce the experimental average heat transfer coefficient with good accuracy, within an error of $15 \%$, despite showing a different overall trend. In lack of a validated correlation, the Cooper method is suggested to predict the heat transfer coefficient of low critical temperature organic fluids during vaporization at high pressures in BPHX.

- Four two-phase frictional pressure drop correlations were compared to the experimental data of the two fluids. All the correlations considerably over-predicted the measured frictional pressure drop. The low saturation temperatures, on which the selected correlations were developed, may explain the deviations.

- A two-phase heat transfer correlation for predicting the presented experimental data of HFC-245fa and HFO1233zd was developed following the prediction method proposed by Amalfi et al. [21]. The power law-type correlation is based on four non-dimensional numbers and present an accuracy suitable for engineering modelling purposes with a coefficient of determination, $\mathrm{R}^{2}$, of $77 \%$.

- A two-phase frictional pressure correlation based on a quadratic term accounting for turbulent phenomena and assuming homogeneous flow was proposed. The equation allowed predicting the experimental data of the two fluids with a coefficient of determination, $\mathrm{R}^{2}$, of $74 \%$.

A first step towards an experimental database comprising experimental data of low temperature organic fluids vaporization at typical evaporating conditions for ORC power systems has been taken. Additional experimental data at high pressures using the same test rig with HFC-134a, HFO-1234yf, HFO-1234ze fluids can be found in Zhang et al. [40]. Further work includes experimental campaigns entailing the study of mixture vaporization and the investigation of brazed plate heat exchangers geometrical parameters.

\section{Acknowledgements}

This work has been carried out during A. Desideri's research period at Technical University of Denmark, Department of Mechanical Engineering, supported by the IWT SBO-110006 project The Next Generation Organic Rankine Cycles (www.orcnext.be), funded by the Institute for the Promotion and Innovation by Science and Technology in Flanders. The authors want to acknowledge the support of the Copenhagen School of Marine Engineering and Technology Management (hours), the Danish Maritime Fund (grant 2014-029) and COWIfonden (grant A-123.10).

\section{References}

[1] Hansen J, Sato M, Hearty P, Ruedy R, Kelley M, Masson-Delmotte V, et al. Ice melt, sea level rise and superstorms: evidence from paleoclimate data, climate modeling, and modern observations that $2 \mathrm{C}$ global warming is highly dangerous. Atmospheric Chemistry and Physics Discussions 2015;15(14):20059-179. doi:10.5194/acpd-15-20059-2015.

[2] Benestad RE, Nuccitelli D, Lewandowsky S, Hayhoe K, Hygen HO, van Dorland R, et al. Learning from mistakes in climate research. Theoretical and Applied Climatology 2015;doi:10.1007/s00704-015-1597-5.

[3] Cook J, Oreskes N, Doran PT, Anderegg WRL, Verheggen B, Maibach EW, et al. Consensus on consensus : a synthesis of consensus estimates on human caused global warming. Environmental Research Letters 2016;11(2016):1-24. doi:10.1088/1748-9326/11/4/048002.

[4] European Commission . Energy prices and costs in Europe 2014;:248doi:10.2765/72195.

[5] Joskow PL. Lessons Learned from Electricity Market Liberalization. The Energy Journal 2008;29(01):9-42. doi:10.5547/ISSN0195-6574EJ-Vol29-NoSI2-3.

[6] Akorede MF, Hizam H, Pouresmaeil E. Distributed energy resources and benefits to the environment. Renewable and Sustainable Energy Reviews 2010;14(2):724-34. doi:10.1016/j.rser.2009.10.025.

[7] Geller H, Harrington P, Rosenfeld AH, Tanishima S, Unander F. Polices for increasing energy efficiency: Thirty years of experience in OECD countries. Energy Policy 2006;34(5):556-73. doi:10.1016/j.enpol.2005.11.010.

[8] Hammond GP, Norman JB. Heat recovery opportunities in UK industry. Applied Energy 2014;116:387-97. doi:10.1016/j.apenergy.2013.11.008.

[9] DOE. Waste Heat Recovery: Technology Opportunities in the US Industry. Tech. Rep.; U.S. Department of energy Industrial Technologies Program; 2008. 
[10] IEA. Industrial Excess Heat Recovery Technologies \& Applications. Tech. Rep.; Industrial Energy-related Technologies and Systems (IETS); 2010

[11] Pehnt M, Bödeker J, Arens M. Industrial waste heat tapping into a neglected efficiency potential. ECEE 2011 Summer Study 2011;:691-700.

[12] Angelino G, Bini R, Bombarda P, Gaia M, Girardi P, Lucchi P, et al. One MW binary cycle turbogenerator module made in europe. In: Proceedings of the World Geothermal Congress; vol. 3. 1994, p. 2125-30.

[13] Angelino G, Gaia M, Macchi E. A review of italian activity in the field of organic Rankine cycles. Verein Deutscher Ingenieure Berichte 539 $1984 ;: 465-82$.

[14] Walraven D. LB, D haeseleer W. Comparison of thermodynamic cycles for power production from low-temperature geothermal heat sources. Energy Conversion and Management 2013;66(0):220 -33. doi:http://dx.doi.org/10.1016/j.enconman.2012.10.003.

[15] Declaye S, Quoilin S, Guillaume L, Lemort V. Experimental study on an open-drive scroll expander integrated into an ORC (organic Rankine cycle) system with R245fa as working fluid. Energy 2013;55(0):173 -83. doi:http://dx.doi.org/10.1016/j.energy.2013.04.003.

[16] Quoilin S, van den Broek M, Declaye S, Dewallef P, Lemort V. Techno-economic survey of organic Rankine cycle ORC systems. Renewable and Sustainable Energy Reviews 2013;22:168-86. doi:10.1016/j.rser.2013.01.028.

[17] Colonna P, van Putten H. Dynamic modeling of steam power cycles. Part I - Modeling paradigm and validation. Applied Thermal Engineering 2007;27(23):467 -80. doi:http://dx.doi.org/10.1016/j.applthermaleng.2006.06.011.

[18] Hernandez A, Desideri A, Ionescu C, Keyser RD, Lemort V, Quoilin S. Real-time optimization of organic Rankine cycle systems by Extremum-Seeking control. Energies 2016; doi:10.3390/en9050334.

[19] Desideri A, Dechesne B, Wronski J, Broek MVD, Sergei G, Lemort V, et al. Comparison of Moving Boundary and Finite-Volume Heat Exchanger Models in the Modelica Language. Energies 2016;:1-17doi:10.3390/en9050339.

[20] Karellas S, Schuster A, Leontaritis AD. Influence of supercritical ORC parameters on plate heat exchanger design. Applied Thermal Engineering 2012;33-34:70-6. doi:10.1016/j.applthermaleng.2011.09.013.

[21] Amalfi RL, Vakili-Farahani F, Thome JR. Flow boiling and frictional pressure gradients in plate heat exchangers. Part 2: Comparison of literature methods to database and new prediction methods. International Journal of Refrigeration 2016;61:185-203. doi:10.1016/j.ijrefrig.2015.07.009.

[22] Claesson J. Thermal and Hydraulic Performance of Compact Brazed Plate Heat Exchangers Operating as Evaporators in Domestic Heat Pumps. Doctoral thesis; Royal Institute of Technology, KTH; 2004.

[23] Webb RL, Gupte NS. A Critical Review of Correlations for Convective Vaporization in Tubes and Tube Banks. Heat Transfer Engineering 1992;13(3):58-81. doi:10.1080/01457639208939782.

[24] García-Cascales J, Vera-García F, Corberán-Salvador J, Gonzálvez-Maciá J. Assessment of boiling and condensation heat transfer correlations in the modelling of plate heat exchangers. International Journal of Refrigeration 2007;30(6):1029-41. doi:10.1016/j.ijrefrig.2007.01.004

[25] Danilova G, Azarskov V, Zemskov B. Plastinchatihispariteljan razichnole geometri heat transfer in plate evaporators of different geometry. Kholod Tek 1981;

[26] Thonon B, Vidil R, Marvillet C. Recent research and developments in Plate Heat Exchangers. Journal of Enhanced heat transfer 1995;2:14955.

[27] Yan YY, Lin TF. Evaporation Heat Transfer and Pressure Drop of Refrigerant R-134a in a Plate Heat Exchanger. Journal of Heat Transfer 1999;121(1):118. doi:10.1115/1.2825924.

[28] Hsieh Y, Lin T. Saturated flow boiling heat transfer and pressure drop of refrigerant R-410A in a vertical plate heat exchanger. International Journal of Heat and Mass Transfer 2002;45(5):1033-44. doi:10.1016/S0017-9310(01)00219-8.

[29] Hsieh YY, Lin TF. Evaporation Heat Transfer and Pressure Drop of Refrigerant R-410A Flow in a Vertical Plate Heat Exchanger. Journal of Heat Transfer 2003;125(5):852. doi:10.1115/1.1518498.

[30] Han DH, Lee KJ, Kim YH. Experiments on the characteristics of evaporation of R410A in brazed plate heat exchangers with different geometric configurations. Applied Thermal Engineering 2003;23(10):1209-25. doi:10.1016/S1359-4311(03)00061-9.

[31] Palm B, Claesson J. Plate Heat Exchangers: Calculation Methods for Singleand Two-Phase Flow. Heat Transfer Engineering 2006;27(4):8898. doi:10.1080/01457630500523949.

[32] Cooper M. Flow boilingthe apparently nucleate regime. International Journal of Heat and Mass Transfer 1989;32(3):459-64. doi:10.1016/0017-9310(89)90133-6.

[33] Longo G, Gasparella A. Heat transfer and pressure drop during HFC refrigerant vaporisation inside a brazed plate heat exchanger. International Journal of Heat and Mass Transfer 2007;50(25-26):5194-203. doi:10.1016/j.ijheatmasstransfer.2007.07.001.

[34] Gorenflo D. Pool boiling. VDI Heat Atlas 1993;

[35] Longo GA. Hydrocarbon Refrigerant Vaporization Inside a Brazed Plate Heat Exchanger. Journal of Heat Transfer 2012;134(10):101801. doi:10.1115/1.4006817.

[36] Khan MS, Khan TS, Chyu MC, Ayub ZH. Experimental investigation of evaporation heat transfer and pressure drop of ammonia in a 30 chevron plate heat exchanger. International Journal of Refrigeration 2012;35(6):1757-65. doi:10.1016/j.ijrefrig.2012.05.019.

[37] Datla BV, Brasz JJ, Turbo S, Llc M. Comparing R1233zd and R245fa for Low Temperature ORC Applications. In: 15th International Refrigeration and Air Conditioning Conference at Purdue. Purdue; 2014, p. 1-7.

[38] Guillaume L, Legros A, Desideri A, Lemort V. Performance of a radial-inflow turbine integrated in an ORC system and designed for a WHR on truck application: An experimental comparison between R245fa and R1233zd. Applied Energy 2016;(March). doi:10.1016/j.apenergy.2016.03.012.

[39] Desideri A, Ommen T, Wronski J, Quoilin S, Lemort V, Haglind F. Experimental results for hydrocarbon refrigerant vaporization in brazed plate heat exchangers at high pressure. In: 16th International Refrigeration and Air Conditioning Conference at Purdue. 2016,.

[40] Zhang J, Desideri A, Ryhl Kaern M, Haglind F. Flow boiling heat transfer and pressure drop characteristics of r134a, r1234yf and r1234ze in a plate heat exchanger with conditions prevailing in the evaporator of organic rankine cycle units. Submitted for publication 2016;.

[41] Amalfi RL, Vakili-Farahani F, Thome JR. Flow boiling and frictional pressure gradients in plate heat exchangers: part 1, review and experimental database. International Journal of Refrigeration 2015;doi:10.1016/j.ijrefrig.2015.07.010.

[42] Shah RK. Assessment of modified wilson plot techniques for obtaining heat exchanger design data. In: The Ninth international heat transfer 
Conference. ISBN 0891169091; 1990,.

[43] CEPSA. Thexatherm thermophisical properties. 2016. URL: www.cepsa.com/; online; accessed 2016-07-29.

[44] ITS90 . International temperature scale of 1990. Tech. Rep.; ITS90; 1991.

[45] Bell I, Wronski J, Quoilin S, Lemort V. Pure- and pseudo-pure fluid thermophysical property evaluation and the open-source thermophysical property library CoolProp. Industrial \& Engineering Chemistry Research 2014;53:2498-508.

[46] Martin H. Pressure Drop and Heat Transfer in Plate Heat Exchangers 2010;:1609doi:10.1007/978-3-540-77877-6.

[47] Sherbini A, Joardar a, Jacobi A. Modified Wilson-Plot Technique for Heat Exchanger Performance: Strategies for Minimizing Uncertainty in Data Reduction. International Refrigeration and Air Conditioning Conference 2004;:1-8.

[48] Jones E, Oliphant T, Peterson P, et al. SciPy: Open source scientific tools for Python. 2001. URL: http://www.scipy.org/; online; accessed 2016-07-29.

[49] Maslov A, Kovalenko M. Hydraulic resistance and heat transfer in plate heat exchangers. Molochnuya Promyshlennost 1972;(10):20-2.

[50] Rosenblad G, Kullendroff A. Estimating heat trans- fer from mass transfer studies on plate heat exchanger sur- faces. Warmeund Stoffubertragung 1975;8(3):187-91.

[51] Talik AC, Fletcher LS, Anand NK, Swanson LW. Heat transfer and pressure drop characteristics of a plate heat exchanger. In: Proceedings of the ASME/JSME Thermal Engineering Conference; vol. 4. New York: ASME; 1995, p. 321-9.

[52] Talik AC, Fletcher LS, Anand NK, Swanson LW. Heat transfer and pressure drop characteristics of a plate heat exchanger using a propyleneglycol/water mixture as the working fluid. In: 30th National Heat Transfer Con- ference; vol. 12. New York: ASME; 1995, p. 83-8.

[53] Wanniarachchi A, Ratman U, Tilton B, Dutta-Roy K. Approximate correlations for chevron-type plate heat exchangers. In: National Heat Transfer Conference; vol. 12. ASME; 1995, p. 145-51.

[54] Bogaerts R, Bolcs A. Global performance of a prototype brazed plate heat exchanger in a large reynolds number range. Experimental Heat transfer 1995;:293-311.

[55] Kline S, McClintock F. Describing uncertainties in single sample experiments. Mechanical Engineering 1953;

[56] Steiner D. Flow boiling heat transfer in vertical tubes correlated by an asymptotic model. Heat transfer engineering 1982;.

[57] Shiferaw D, Karayiannis T, Kenning D. Flow boiling in a $1.1 \mathrm{~mm}$ tube with R134a: Experimental results and comparison with model. International Journal of Thermal Sciences 2009;48(2):331-41. doi:10.1016/j.ijthermalsci.2008.02.009.

[58] Copetti JB, Macagnan MH, Zinani F, Kunsler NL. Flow boiling heat transfer and pressure drop of R-134a in a mini tube: an experimental investigation. Experimental Thermal and Fluid Science 2011;35(4):636-44. doi:10.1016/j.expthermflusci.2010.12.013.

[59] Gungor K, Winterton R. A general correlation for flow boiling in tubes and annuli. International Journal of Heat and Mass Transfer 1986;29(3):351-8. doi:10.1016/0017-9310(86)90205-X.

[60] Shah MM. Chart correlation for saturated boiling heat transfer equations and further study. ASHRAE Transactions 1982;.

[61] Cooper M. Heat Flow Rates in Saturated Nucleate Pool Boiling-A Wide-Ranging Examination Using Reduced Properties. Advances in Heat Transfer 1984;16:157-239. doi:10.1016/S0065-2717(08)70205-3.

[62] Eldeeb R, Aute V, Radermacher R. A Model for Performance Prediction of Brazed Plate Condensers with Conventional and Alternative Lower GWP Refrigerants. In: International refrigeration and air conditioning Conference. Purdue University. ISBN 3014058726; 2014, p. $1-10$.

[63] Ayub ZH. Plate Heat Exchanger Literature Survey and New Heat Transfer and Pressure Drop Correlations for Refrigerant Evaporators. Heat Transfer Engineering 2003;24(5):3-16. doi:10.1080/01457630304056.

[64] Vakili-Farahani F, Amalfi RL, Thome JR. Two-Phase Flow and boiling of R-245fa in a $1 \mathrm{~mm}$ pressing depth plate heat exchanger Part I : Adiabatic pressure Drop. Interfacial Phenomena and Heat Transfer 2014;2(4):325-42.

[65] Desideri A, Hernandez A, Gusev S, van den Broek M, Lemort V, Quoilin S. Steady-state and dynamic validation of a small-scale waste heat recovery system using the thermocycle modelica library. Energy 2016;115, Part 1:684 -96. doi:http://dx.doi.org/10.1016/j.energy.2016.09.004

[66] Briggs D, Young E. Modified wilson plot techniques for obtaining heat transfer correlations for shell and tube heat exchangers. Chel Eng Progr Symp Ser 1969;65(92):35-45. 